\title{
Long-term mechanical circulatory support (destination therapy): On track to compete with heart transplantation?
}

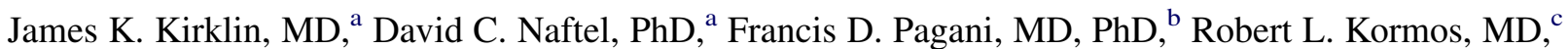 \\ Lynne Stevenson, MD, ${ }^{\mathrm{d}}$ Marissa Miller, DVM, MPH, ${ }^{\mathrm{e}}$ and James B. Young, $\mathrm{MD}^{\mathrm{f}}$
}

\begin{abstract}
Objectives: Average 2-year survival after cardiac transplantation is approximately $80 \%$. The evolution and subsequent approval of larger pulsatile and, more recently, continuous flow mechanical circulatory support (MCS) technology for destination therapy (DT) offers the potential for triage of some patients awaiting cardiac transplantation to DT.
\end{abstract}

\begin{abstract}
Methods: The National Heart, Lung, and Blood Institute Interagency Registry for Mechanically Assisted Circulatory Support (INTERMACS) is a national multi-institutional study of long-term MCS. Between June 2006 and December 2011, 127 pulsatile and 1160 continuous flow pumps (24\% of total primary left ventricular assist devices [LVADs]) carried an initial strategy of DT therapy.

Results: By multivariable analysis, risk factors $(P<.05)$ for mortality after DT included older age, larger body mass index, history of cancer, history of cardiac surgery, INTERMACS level I (cardiogenic shock), dialysis, increased blood urea nitrogen, use of a pulsatile flow device, and use of a right ventricular assist device (RVAD). Among patients with a continuous flow LVAD who were not in cardiogenic shock, a particularly favorable survival was associated with no cancer, patients not in cardiogenic shock, and blood urea nitrogen less than 50 $\mathrm{mg} / \mathrm{dL}$, resulting in 1- and 2-year survivals of $88 \%$ and $80 \%$.

Conclusions: (1) Evolution from pulsatile to continuous flow technology has dramatically improved 1- and 2-year survivals; (2) DT is not appropriate for patients with rapid hemodynamic deterioration or severe right ventricular failure; (3) important subsets of patients with continuous flow DT now enjoy survival that is competitive with heart transplantation out to about 2 years. (J Thorac Cardiovasc Surg 2012;144:584-603)
\end{abstract}

Durable mechanical circulatory support (MCS) systems have evolved into therapies suitable for multiyear support. In the United States, the historical development of such support devices was linked to cardiac transplantation, addressing the universal shortage of suitable donors for cardiac transplantation. The vast majority of durable devices have

From Cardiothoracic Surgery, ${ }^{a}$ University of Alabama at Birmingham, Birmingham, Ala; Cardiac Surgery, ${ }^{\mathrm{b}}$ University of Michigan, Ann Arbor, Mich; Cardiothoracic Surgery, ${ }^{\mathrm{c}}$ University of Pittsburgh, Pittsburgh, Pa; Cardiovascular Medicine, ${ }^{\mathrm{d}}$ Brigham and Women's Medical Center, Boston, Mass; National Heart Lung and Blood Institute (NHLBI), ${ }^{\mathrm{e}}$ Bethesda, Md; and Cardiovascular Disease, ${ }^{\mathrm{f}}$ Cleveland Clinic Foundation, Cleveland, Ohio.

This work was sponsored by the National Institutes of Health, National Heart, Lung, and Blood Institute (NHLBI), Registry of Mechanical Circulatory Support Devices for End-Stage Heart Failure (INTERMACS). Contract No. HHSN268200548198C.

Disclosures: Dr Kirklin is Princpal Investigator for INTERMACS. Dr Pagani has a research contract with the NHLBI and HeartWare for the REVIVE-IT trial and HeartWare for the ENDURANCE trial. All contracts are managed by the University of Michigan. Dr Naftel receives research funding from Thoratec but no salary. He is a consultant for HeartWare. All remaining authors have nothing to disclose with regard to commercial support.

Read at the 92nd Annual Meeting of The American Association for Thoracic Surgery, San Francisco, California, April 28-May 2, 2012.

Received for publication April 6, 2012; revisions received April 6, 2012; accepted for publication May 16, 2012; available ahead of print July 16, 2012.

Address for reprints: James K. Kirklin, MD, University of Alabama at Birmingham, THT 760, 1900 University Blvd, Birmingham, AL 35294 (E-mail: jkirklin@uab. edu).

0022-5223/\$36.00

Copyright (C) 2012 by The American Association for Thoracic Surgery

http://dx.doi.org/10.1016/j.jtcvs.2012.05.044 been implanted as bridge-to-transplant therapy, with a small subset implanted as a bridge-to-ventricular recovery. When MCS therapy in the United States was expanded to include the intent of long-term "destination" therapy (DT) in $2003,{ }^{1}$ Medicare and most other providers considered DT appropriate only for patients not considered eligible for cardiac transplantation, based on inferior demonstrated survival with MCS compared with transplantation.

However, the landscape of devices, their expected durability, and patient outcomes have rapidly evolved over the past 4 years. This study was undertaken to examine, through a national MCS database, the hypothesis that "mechanical circulatory support as DT has evolved to a level that justifies consideration of selected patients for DT who are transplant eligible."

\section{MATERIALS AND METHODS \\ Interagency Registry for Mechanically Assisted Circulatory Support Database}

Interagency Registry for Mechanically Assisted Circulatory Support (INTERMACS) is a registry for durable (suitable for patient discharge) MCS devices approved by the US Food and Drug Administration (FDA) and implanted in the United States. The registry is sponsored by the National Heart, Lung, and Blood Institute (NHLBI). The term "interagency" emphasizes the unique collaboration between the NHLBI as the funding and scientific support agency, the FDA as the regulatory agency, and the Center for Medicaid and Medicare Services (CMS) as the federal reimbursement agency. ${ }^{2}$ Information collected in the INTERMACS database 


\section{Abbreviationsand Acronyms \\ CMS $\quad=$ Center for Medicaid and Medicare Services \\ DT $\quad=$ destination therapy \\ EQ $\quad=$ EuroQol \\ FDA $\quad=$ Food and Drug Administration \\ INTERMACS $=$ Interagency Registry for Mechanically Assisted \\ Circulatory Support \\ LVAD $=$ left ventricular assist device \\ MCS = mechanical circulatory support \\ NHLBI = National Heart, Lung, and Blood \\ Institute \\ NYHA $=$ New York Heart Association \\ RVAD = right ventricular assist device \\ VAD $=$ ventricular assist device}

\section{Missing DT Patients From INTERMACS}

Patients receiving MCS implants in the United States who are entered into INTERMACS must fulfill 2 criteria: (1) the device implanted must be FDA approved and (2) the patient must provide informed consent for entry of his or her data into INTERMACS. For FDA-approved devices, INTERMACS receives data on device implant and survival/mortality at 48 hours for all patients, even if consent is not obtained. Further followup is available only if patient consent is obtained. INTERMACS audits and screening logs indicate that $9.6 \%$ of patients suitable for INTERMACS were not entered with full data collection owing to failure to obtain informed consent. INTERMACS receives no information for patients who receive an investigational device as part of a clinical trial.

\section{Follow-up}

All patients are followed up as part of the requirements of INTERMACS until 1 of 3 end points is reached: death, transplant, or device explant for recovery. Data collection at routine follow-up intervals (see Appendix Table 1) occurs for a variety of routine clinical variables in addition to data forms that are "triggered" by specific adverse events. Among the 1287 DT patients, follow-up was available in greater than $99 \%$ at the follow-up date of December 31, 2011.

\section{Adverse Event Definitions}

Standardized definitions for adverse events were established during the initial phase of INTERMACS, developed with the participation and agreement of experts in the field, FDA, and industry. The adverse event definitions are included in Appendix Table 2.

\section{INTERMACS Profiles}

The INTERMACS profiles represent a reclassification of New York Heart Association (NYHA) class IV heart failure. ${ }^{3}$ The profiles are listed in Appendix Table 3.

\section{Statistical Methods}

Standard Kaplan-Meier actuarial methods as well as parametric depictions were used to examine survival and freedom from other specific events. Standard methods were used to examine whether differences among variables were likely due to chance. Competing outcomes depictions used standard methodology as described by McGiffin and colleagues. ${ }^{4}$ Risk the overall experience, 127 DT implants were pulsatile devices and 1160 were continuous flow pumps (see again Figure 1).

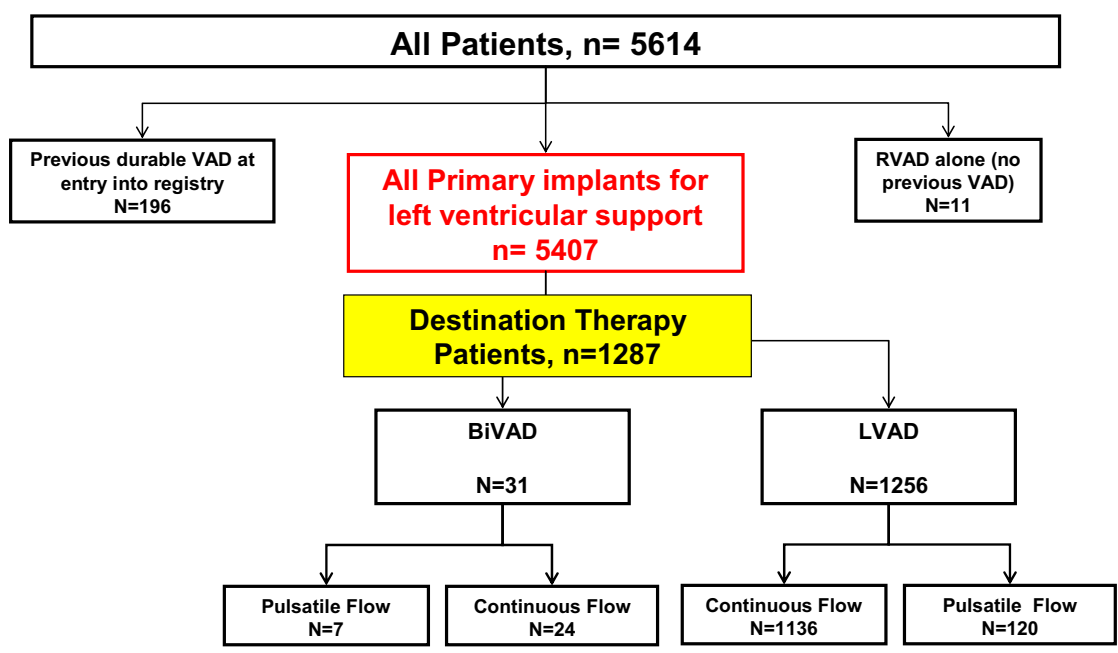

FIGURE 1. Categorization of all 5614 patients entered into INTERMACS between June 23, 2006, and December 31, 2011. The group Destination Therapy $(\mathrm{n}=1287)$ constitutes the study group. INTERMACS, Interagency Registry for Mechanically Assisted Circulatory Support; VAD, ventricular assist device; $R V A D$, right ventricular assist device; $L V A D$, left ventricular assist device; BiVAD, biventricular assist device. 
TABLE 1. INTERMACS June 2006-December 2011: Destination therapy

Inclusion/exclusion criteria

Primary LVAD or BIVAD implant

Adults (aged $\geq 19$ y at implant)

Patients consented to participate in INTERMACS

Device strategy at time of implant: destination therapy

Patient received an FDA-approved device

Implant dates: June 23, 2006-December 31, 2011

Study group description

Institutions contributing data: 104

Patients: 1287

Total deaths with a device in place: 314

Total heart transplants: 52

Total device removal due to recovery: 3

Total device exchanges: 52

Total transfers*: 11

Follow-up: through December 31, 2011

LVAD, Left ventricular assist device; BIVAD, biventricular assist device; INTER$M A C S$, Interagency Registry for Mechanically Assisted Circulatory Support; FDA, United States Food and Drug Administration. *Eleven patients had their care transferred to a non-INTERMACS center and were censored at the time of care transfer.

factors for mortality were examined via multivariable analysis in the hazard function domain. The variables entered into the multivariable model are listed in Appendix Table 4. The risk factor equations are listed in Appendix Table 5.

\section{Transplant Survival}

Expected survival after cardiac transplantation was drawn from the registry of the International Society for Heart and Lung Transplantation. ${ }^{5}$

\section{Quality of Life Studies}

All institutions were encouraged to apply quality of life instruments to patients receiving MCS, beginning before implantation and repeated at specified intervals thereafter. The selected quality of life instruments included the EuroQol (EQ)-5D and the EQ visual analog scale score. The EQ-5D is a standardized instrument designed as a measure of health outcome and applicable to a wide range of health conditions and treatments. This test is primarily designed for self-completion by the respondents, examining the dimensions of mobility, self-care, usual activities, pain/discomfort, and anxiety/depression. The EQ visual analog scale instrument includes a standard vertical $20-\mathrm{cm}$ visual analog scale (similar to a thermometer) for recording an individual's self-rating regarding his or her personal general health-related quality of life state.

\section{RESULTS \\ Evolution of DT}

During the early phase of INTERMACS, continuous flow technology was not yet FDA approved for adult patients. During the era in which essentially only pulsatile pumps were entered into INTERMACS (June 2006-December 2007), only $13 \%$ of pumps were implanted with a strategy of DT. With the approval of the HeartMate II continuous flow device (Thoratec Corporation, Pleasanton, Calif) for DT in January 2010, the number and proportion of pumps implanted as DT progressively increased (Table 2 ). During the year $2011,96 \%$ of primary device implants (for any strategy) were continuous flow pumps (Figure 2). DT accounted for $38 \%$ of implants during 2011, and all DT patients received continuous flow devices (Figure 3).

\section{Reasons for Transplant Ineligibility}

A variety of contraindications to transplants were cited, some of which were absolute while others were potentially reversible during VAD support (Table 3 ). The most frequently cited contraindication was advanced age (38\% of patients), followed by renal dysfunction ( $20 \%)$, high body mass index $(14 \%)$, and pulmonary hypertension $(12 \%)$. Approximately $35 \%$ were considered potentially modifiable, indicating the possibility of later suitability for transplantation.

\section{Outcome of Patients With Initial DT Strategy}

As noted in the previous section, many of the contraindications to transplantation at the time of device implant were considered potentially reversible. As their clinical situation evolved over time, some patients were reconsidered for cardiac transplantation, or, potentially, for device explant. These events are tracked by the competing outcomes depictions in Figure 4 for pulsatile devices and Figure 5 for continuous flow devices. In the current era of continuous flow

TABLE 2. Primary device strategy by year of implant: June 2006-December 2011

\begin{tabular}{|c|c|c|c|c|c|c|c|}
\hline \multicolumn{8}{|c|}{ Implant year } \\
\hline Device strategy & $\begin{array}{c}2006 \\
\text { No. }(\%)\end{array}$ & $\begin{array}{c}2007 \\
\text { No. }(\%)\end{array}$ & $\begin{array}{c}2008 \\
\text { No. }(\%)\end{array}$ & $\begin{array}{c}2009 \\
\text { No. }(\%)\end{array}$ & $\begin{array}{c}2010 \\
\text { No. }(\%)\end{array}$ & $\begin{array}{c}2011 \\
\text { No. }(\%)\end{array}$ & Total \\
\hline Bridge to recovery & $4(3.9)$ & $14(4.0)$ & $15(2.0)$ & $12(1.2)$ & $12(0.8)$ & $15(0.9)$ & 72 \\
\hline Bridge to transplant* & $45(43.7)$ & $148(42.6)$ & $367(49.4)$ & $491(49.4)$ & $463(28.9)$ & $370(22.8)$ & 1884 \\
\hline Bridge-to-transplant candidacy & $36(35.0)$ & $132(38.0)$ & $302(40.6)$ & $433(43.6)$ & $598(37.4)$ & $600(37.0)$ & 2101 \\
\hline Destination therapy $\dagger$ & $16(15.6)$ & $47(13.5)$ & $47(6.3)$ & $47(4.7)$ & $511(31.9)$ & $620(38.3)$ & $1288 \ddagger$ \\
\hline Rescue therapy & $2(1.9)$ & $6(1.7)$ & $12(1.6)$ & $5(0.5)$ & $8(0.5)$ & $5(0.3)$ & 38 \\
\hline Other & $0(0.00)$ & $0(0.00)$ & $0(0.00)$ & $5(0.5)$ & $9(0.6)$ & $10(0.6)$ & 24 \\
\hline Total & 103 & 347 & 743 & 993 & 16014 & 1620 & 5407 \\
\hline
\end{tabular}

*Patient currently listed for transplant. †Patient definitely not eligible for transplant. $\ddagger$ One patient, aged 18 years, was considered a pediatric patient and was not included in the study group. 


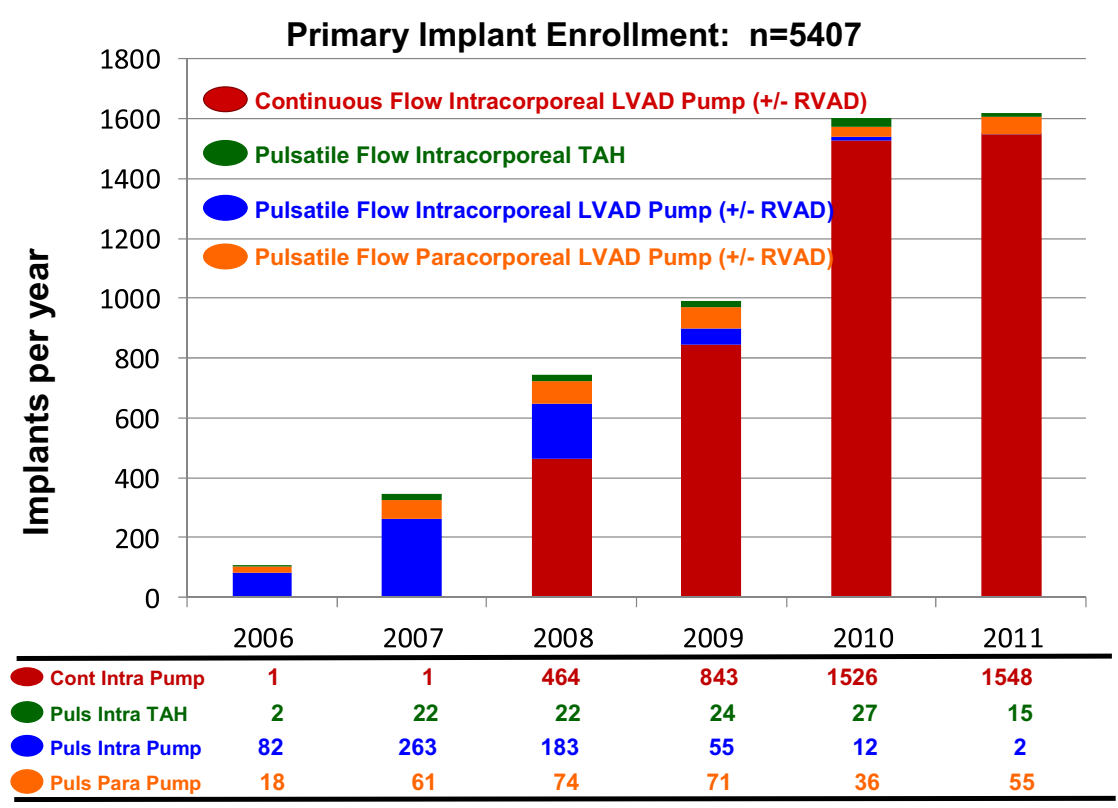

FIGURE 2. Primary device implant by year, stratified by device type, for the entire INTERMACS experience. INTERMACS, Interagency Registry for Mechanically Assisted Circulatory Support; LVAD, left ventricular assist device; RVAD, right ventricular assist device; TAH, total artificial heart; Cont, continuous flow; Intra, intracorporeal; Puls, pulsatile; Para, paracorporeal.

DT devices, less than $5 \%$ of patients undergo transplantation or explant within 2 years.

\section{Adverse Events}

Infection and bleeding were the most common adverse events, followed by respiratory failure, neurologic events, and renal dysfunction (Table 4). Of note, the adverse event profile differed between pulsatile and continuous flow pumps (Table 4). Device malfunction, bleeding, infection, stroke, renal dysfunction, and respiratory failure all occurred with a significantly higher event rate with pulsatile pumps.

Device malfunction severe enough to require pump exchange or cause death was strikingly different between pump types (Figure 6). The hazard function (instantaneous risk) for device failure progressively increased over the 2 years of follow-up for pulsatile pumps, whereas the hazard function for continuous flow devices

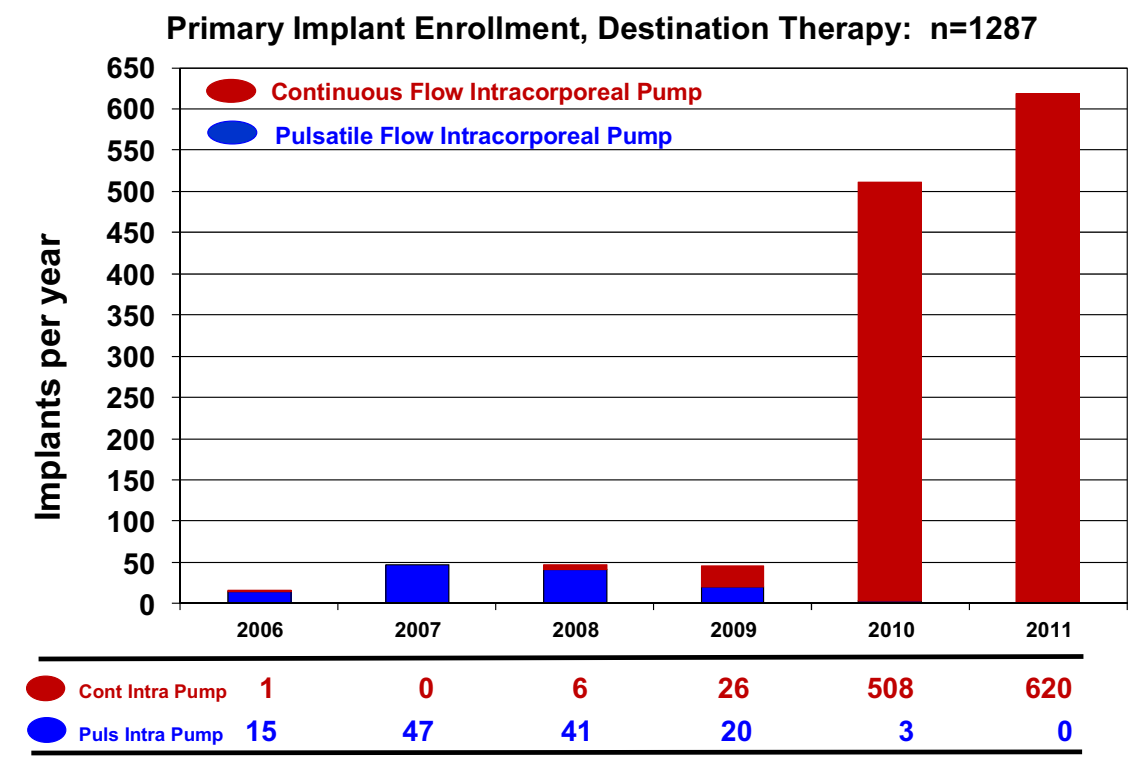

FIGURE 3. Destination therapy device implants by year, stratified by device type. Cont, Continuous flow; Intra, intracorporeal; Puls, pulsatile. 
TABLE 3. Transplant contraindications-Adult primary implants: INTERMACS June 2006-December 2011

\begin{tabular}{lc}
\hline \multicolumn{1}{c}{ Contraindications } & No. $(\%)$ \\
(N $=\mathbf{1 2 8 7})$ \\
\hline Modifiable & \\
Renal dysfunction & $256(20)$ \\
High body mass index & $182(14)$ \\
Pulmonary hypertension & $157(12)$ \\
Still smoking & $90(7)$ \\
Severe diabetes & $87(7)$ \\
Alcohol abuse & $41(3)$ \\
Illicit drug use & $40(3)$ \\
Repeated noncompliance & $40(3)$ \\
Limited social support & $38(3)$ \\
Limited cognition/understanding & $21(1.6)$ \\
Malnutrition/cachexia & $20(1.6)$ \\
Severe depression & $10(0.8)$ \\
Musculoskeletal limitation & $10(0.8)$ \\
Risk of recurrent infection & $9(0.7)$ \\
Current infection & $9(0.7)$ \\
Heparin-induced thrombocytopenia & $9(0.7)$ \\
Recent pulmonary embolus & $3(0.2)$ \\
Nonmodifiable & \\
Advanced age & $487(38)$ \\
Peripheral vascular disease & $89(7)$ \\
Pulmonary disease & $80(6)$ \\
History of solid-organ cancer & $64(5)$ \\
Patient refuses transplant & $54(4)$ \\
Frailty & $48(4)$ \\
Fixed pulmonary hypertension & $41(3)$ \\
Multiple sternotomies & $32(2)$ \\
Mistory of lymphoma leukemia & $29(2)$ \\
Contraindication to immunotherapy & $18(1.4)$ \\
Other major psychiatric diagnosis & $15(1.2)$ \\
Allosensitization & $8(0.6)$ \\
Mediastinal radiation & $6(0.5)$ \\
Thoracic aortic disease & $4(0.3)$ \\
\hline Other comorbidity & $40.3)$ \\
\hline
\end{tabular}

INTERMACS, Interagency Registry for Mechanical Circulatory Support.

remained low and essentially constant. For pulsatile pumps, the freedom from device exchange was only $51 \%$ at 24 months, compared with $94 \%$ for continuous flow pumps.

\section{Survival}

The overall actuarial survival among all DT patients was $75 \%$ at 1 year and $62 \%$ at 2 years (Figure 7 ). The hazard function shows a rapidly falling early phase that merges with a constant phase at about 3 months.

\section{Cause of Death}

The primary causes of death differed according to time interval after implant as well as device type (Tables 5 and 6). Cardiac failure was the major cause of early mortality,

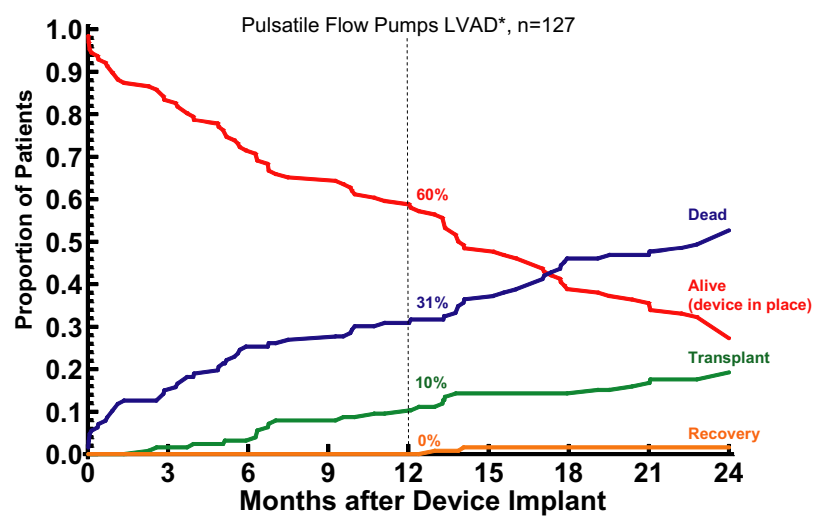

FIGURE 4. Competing outcomes depiction for pulsatile flow left ventricular assist devices ( $L V A D)$ implanted with a strategy of destination therapy. All outcome events are mutually exclusive, such that the sum of all probabilities at any point in time equals $100 \%$. *Includes LVAD only as well as LVAD plus an RVAD implanted for right ventricular failure at the original LVAD implant or anytime thereafter.

and $32 \%$ of those patients received their device while in cardiogenic shock. No other specific cause of death was predominantly related to either device type or interval from implant to death.

\section{Risk Factors for Mortality}

Risk factors for mortality in the early and constant phases identified by multivariable analysis are listed in Table 7 .

Older age. The hazard ratio of 1.24 reflects the increase in risk from age 60 to 70 years. Perhaps not surprising is the finding that elderly patients receiving DT had a lower general risk profile than did younger patients. Without risk adjustment, the actuarial survival for older and younger patients was similar (Figure 8).

INTERMACS level 1. INTERMACS level 1 identifies those patients in cardiogenic shock at the time of VAD implant (see Appendix Table 3). The progressive decrease in

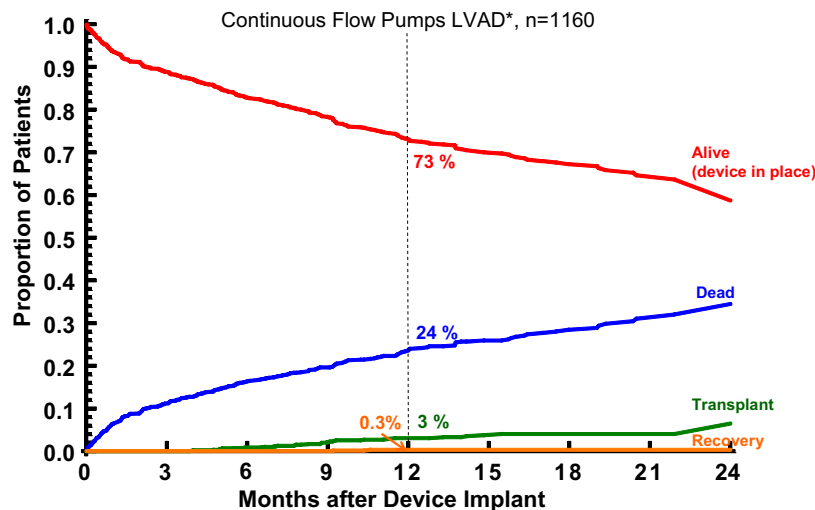

FIGURE 5. Competing outcomes depiction for continuous flow left ventricular assist devices ( $L V A D)$ implanted with a strategy of destination therapy. *The depiction is as in Figure 4. 
TABLE 4. Adverse event rates (events/100 patient-months) in the first 12 months for destination therapy patients

\begin{tabular}{|c|c|c|c|c|c|c|}
\hline \multirow[b]{2}{*}{ Adverse event } & \multicolumn{2}{|c|}{ Pulsatile $(n=127)$} & \multicolumn{2}{|c|}{ Continuous $(\mathrm{n}=1160)$} & \multirow{2}{*}{$\frac{\text { Hazard }}{\text { Ratio }}$} & \multirow[b]{2}{*}{$P$ valu } \\
\hline & Events & Rate & Events & Rate & & \\
\hline Device malfunction & 38 & 3.69 & 100 & 1.15 & 3.21 & $<.0001$ \\
\hline Bleeding & 150 & 14.56 & 1040 & 11.94 & 1.22 & .008 \\
\hline \multicolumn{7}{|l|}{ Cardiac/vascular } \\
\hline Right heart failure & 14 & 1.36 & 151 & 1.73 & 0.78 & .75 \\
\hline Myocardial infarction & 0 & 0.00 & 3 & 0.03 & - & - \\
\hline Cardiac arrhythmia & 55 & 5.34 & 339 & 3.89 & 1.37 & .009 \\
\hline Pericardial drainage & 10 & 0.97 & 54 & 0.62 & 1.57 & .06 \\
\hline Hypertension* & 27 & 2.62 & 73 & 0.84 & 3.13 & $<.0001$ \\
\hline Arterial non-CNS thrombosis & 5 & 0.49 & 17 & 0.20 & 2.49 & .01 \\
\hline Venous thrombotic event & 11 & 1.07 & 56 & 0.64 & 1.66 & .03 \\
\hline Hemolysis & 0 & 0.00 & 55 & 0.63 & - & - \\
\hline Infection & 236 & 22.91 & 705 & 8.09 & 2.83 & $<.0001$ \\
\hline Neurologic dysfunction & 30 & 2.91 & 162 & 1.86 & 1.57 & .006 \\
\hline Renal dysfunction & 30 & 2.91 & 141 & 1.62 & 1.80 & $<.0001$ \\
\hline Hepatic dysfunction & 7 & 0.68 & 50 & 0.57 & 1.18 & .24 \\
\hline Respiratory failure & 41 & 3.98 & 230 & 2.64 & 1.51 & .004 \\
\hline Wound dehiscence & 10 & 0.97 & 19 & 0.22 & 4.45 & $<.0001$ \\
\hline Psychiatric episode & 21 & 2.04 & 78 & 0.90 & 2.28 & $<.0001$ \\
\hline Total burden & 685 & 66.50 & 3273 & 37.56 & 1.77 & $<.0001$ \\
\hline
\end{tabular}

Hazard ratio, The rate for pulsatile pump divided by the rate for continuous flow pump. CNS, Central nervous system. *With current reporting, identification of hypertension with continuous flow pumps is unreliable.

the proportion of patients in level 1 at implant over the course of the study is documented in Table 8 . The inferior survival when DT was undertaken in the face of cardiogenic shock is apparent in Figure 9.

Severe right ventricular failure. Right ventricular failure sufficient to require support with a biventricular assist device at the time of implant was the strongest predictor of mortality in the constant phase (see again Table 7). The need for biventricular support resulted in a marked

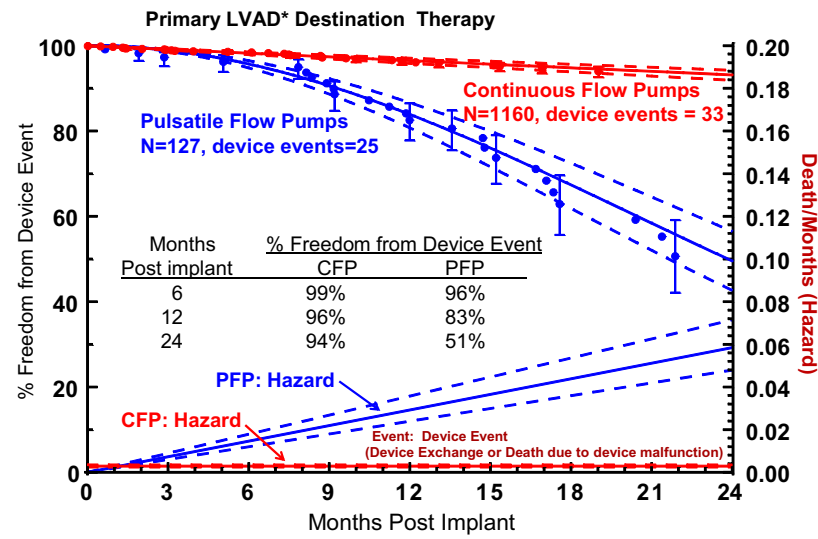

* Includes RVADs implanted at time of LVAD and subsequent RVAD implantations

FIGURE 6. Actuarial freedom from device exchange or death secondary to device malfunction or device complication, stratified by device type. The lower curves represent the hazard function for this event for each device type. The dashed lines enclose the $70 \%$ confidence limits. CFP, Continuous flow pump; PFP, pulsatile flow pump; $L V A D$, left ventricular assist device; $R V A D$, right ventricular assist device. ${ }^{*}$ See notation in Figure 4. reduction in survival for both pulsatile and continuous flow LVADs (Figure 10). The likelihood of right VAD (RVAD) implant at the time of DT was $5.5 \%$ for pulsatile LVADS but fell to $2.1 \%$ with continuous flow technology. Among the 48 RVAD implants, 31 (65\%) occurred at the time of LVAD implant, 2 (4\%) later the same day, 9 $(19 \%)$ between 0 and 7 days, and $6(12 \%)$ more than 7 days after LVAD (Figure 11). RVAD explant occurred in $9(19 \%)$ of 48 patients receiving an RVAD. The duration of RVAD support ranged from 2 to 37 days (mean, 18). The likelihood of needing biventricular support was

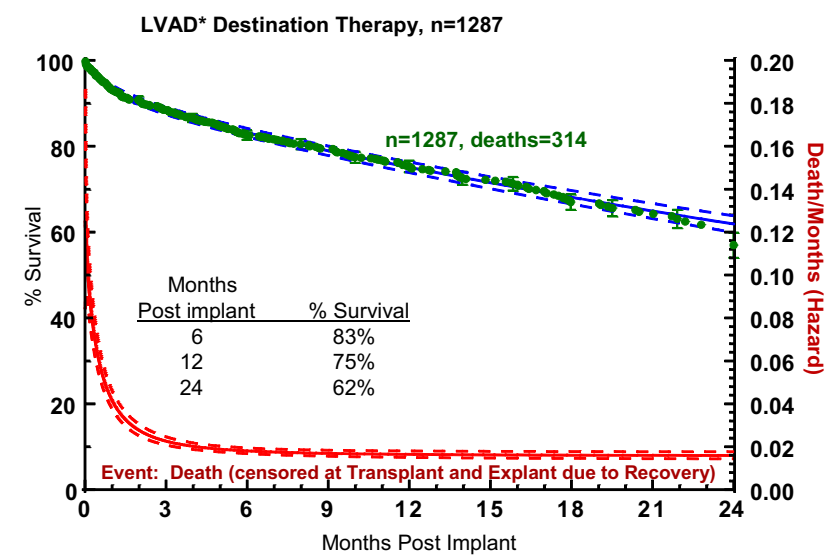

FIGURE 7. Actuarial survival among 1287 patients receiving destination therapy left ventricular assist device ( $L V A D)$ support. Patients are censored at the time of transplant or explant due to recovery. The lower curve represents the hazard function. The dashed lines enclose the $70 \%$ confidence limits. *See notation in Figure 4. 
TABLE 5. Causes of death in 1287 LVAD* destination therapy patients: INTERMACS June 2006-December 2011

\begin{tabular}{|c|c|c|c|c|c|c|}
\hline \multirow{3}{*}{$\begin{array}{c}\text { Primary cause } \\
\text { of death }\end{array}$} & \multicolumn{6}{|c|}{ Pulsatile flow pumps } \\
\hline & \multicolumn{2}{|c|}{$\begin{array}{c}\text { Early }(\leq 1 \text { mo }) \\
(\mathbf{n}=13)\end{array}$} & \multicolumn{2}{|c|}{$\begin{array}{c}\text { Later }(>1 \text { mo }) \\
\quad(n=53)\end{array}$} & \multicolumn{2}{|c|}{$\begin{array}{c}\text { Total } \\
(n=66)\end{array}$} \\
\hline & No. & $\%$ & No. & $\%$ & No. & $\%$ \\
\hline \multicolumn{7}{|l|}{ Cardiac failure } \\
\hline RV failure & 2 & 15 & 4 & 8 & 6 & \\
\hline Arrhythmia/other & 1 & 8 & 6 & 11 & 7 & 11 \\
\hline Infection & 1 & 8 & 8 & 15 & 9 & 14 \\
\hline CNS event & 5 & 38 & 7 & 13 & 12 & 18 \\
\hline Multiorgan failure & 0 & 0 & 3 & 6 & 3 & \\
\hline Respiratory failure & 2 & 15 & 1 & 2 & 3 & \\
\hline \multicolumn{7}{|l|}{ Bleeding } \\
\hline Gastrointestinal & 0 & 0 & 0 & 0 & 0 & \\
\hline Surgical & 1 & 8 & 0 & 0 & 1 & \\
\hline Other bleeding & 1 & 8 & 2 & 4 & 3 & \\
\hline Device failure & 0 & 0 & 3 & 6 & 3 & \\
\hline Renal failure & 0 & 0 & 1 & 2 & 1 & \\
\hline Hepatic failure & 0 & 0 & 1 & 2 & 1 & \\
\hline Malignancy & 0 & 0 & 1 & 2 & 1 & \\
\hline Arterial embolism & 0 & 0 & 0 & 0 & 0 & \\
\hline Cardiac tamponade & 0 & 0 & 0 & 0 & 0 & \\
\hline Withdrawal of support & 0 & 0 & 0 & 0 & 0 & \\
\hline Other & 0 & 0 & 16 & 30 & 16 & 24 \\
\hline Total & 13 & 100 & 53 & 100 & 66 & 100 \\
\hline
\end{tabular}

$L V A D$, Left ventricular assist device; INTERMACS, Interagency Registry for Mechanical Circulatory Support; $R V$, right ventricular; $C N S$, central nervous system. ${ }^{*} \mathrm{In}-$ cludes right ventricular assist devices implanted at the time of or subsequent to left ventricular assist device implantation.

3 times as high for patients in level 1 compared with levels 3 to 7.

Pulsatile pump technology. In this experience, the use of a pulsatile pump yielded inferior survival compared with a current continuous flow device (Figure 12), in which the 1 - and 2-year actuarial survivals were $76 \%$ and $67 \%$. In general, pulsatile pump patients were slightly older and had somewhat worse renal and hepatic function than did continuous flow patients (Table 9).

\section{Quality of Life}

On the basis of the EQ-5D quality of life instruments, patients receiving a continuous flow pump as DT noted a significant reduction $(P<.05)$ in both some and extreme problems with mobility, self-care (Figure 13), usual activities of living (Figure 14), and anxiety/depression, comparing before implant with 3,6 , and 12 months after implant. In the area of pain and discomfort, significantly fewer patients noted this symptom complex after implant, but $6 \%$ of patients interviewed continued to have extreme symptoms of pain and discomfort up to 1 year after LVAD implant. The EQ-5D visual analog scale (see details under Material and Methods) demonstrated prompt improvement within 3 months after VAD implant, which was maintained during the first year after implant (Figure 15).

TABLE 6. Causes of death in 1287 LVAD* destination therapy patients: INTERMACS June 2006-December 2011

\begin{tabular}{|c|c|c|c|c|c|c|}
\hline \multirow{3}{*}{$\begin{array}{c}\text { Primary cause } \\
\text { of death }\end{array}$} & \multicolumn{6}{|c|}{ Continuous flow pumps } \\
\hline & \multicolumn{2}{|c|}{$\begin{array}{c}\text { Early } \\
(\leq \mathbf{1} \mathbf{m o})(n=72)\end{array}$} & \multicolumn{2}{|c|}{$\begin{array}{c}\text { Later } \\
(>1 \text { mo })(n=176)\end{array}$} & \multicolumn{2}{|c|}{$\begin{array}{c}\text { Total } \\
(\mathrm{n}=\mathbf{2 4 8})\end{array}$} \\
\hline & No. & $\%$ & No. & $\%$ & No. & $\%$ \\
\hline \multicolumn{7}{|l|}{ Cardiac failure } \\
\hline RV failure & 6 & 8 & 11 & 6 & 17 & 7 \\
\hline Arrhythmia/other & 12 & 17 & 34 & 19 & 46 & 19 \\
\hline Infection & 5 & 7 & 17 & 10 & 22 & 9 \\
\hline CNS event & 8 & 11 & 15 & 9 & 23 & 9 \\
\hline Multiorgan failure & 12 & 17 & 11 & 6 & 23 & 9 \\
\hline Respiratory failure & 3 & 4 & 9 & 5 & 12 & 5 \\
\hline \multicolumn{7}{|l|}{ Bleeding } \\
\hline Gastrointestinal & 2 & 3 & 2 & 1 & 4 & 2 \\
\hline Surgical & 4 & 6 & 1 & 1 & 5 & 2 \\
\hline Other bleeding & 5 & 7 & 13 & 7 & 18 & 7 \\
\hline Device failure & 0 & 0 & 6 & 3 & 6 & 2 \\
\hline Renal failure & 1 & 1 & 4 & 2 & 5 & 2 \\
\hline Hepatic failure & 2 & 3 & 3 & 2 & 5 & 2 \\
\hline Malignancy & 0 & 0 & 4 & 2 & 4 & 2 \\
\hline Arterial embolism & 0 & 0 & 5 & 3 & 5 & 2 \\
\hline Cardiac tamponade & 0 & 0 & 0 & 0 & 0 & 0 \\
\hline Withdrawal of support & 1 & 1 & 8 & 5 & 9 & 4 \\
\hline Other & 11 & 15 & 33 & 19 & 44 & 18 \\
\hline Total & 72 & 100 & 176 & 100 & 248 & 100 \\
\hline
\end{tabular}

LVAD, Left ventricular assist device; INTERMACS, Interagency Registry for Mechanical Circulatory Support; $R V$, right ventricular; $C N S$, central nervous system. *Includes right ventricular assist devices implanted at the time of or subsequent to left ventricular assist device implantation.

\section{Current Expected Survival After Cardiac Transplantation}

The current average survival after cardiac transplantation, as a benchmark for comparing posttransplant survival against DT, is derived from the most recent International

TABLE 7. Risk factors for death in destination therapy patientsAdult primary implants: INTERMACS, June 2006-December 2011

\begin{tabular}{|c|c|c|c|c|}
\hline \multirow[b]{2}{*}{ Risk factors } & \multicolumn{2}{|c|}{ Early hazard } & \multicolumn{2}{|c|}{ Constant hazard } \\
\hline & HR & $P$ value & HR & $P$ value \\
\hline Age (older) & & & $1.24 *$ & .01 \\
\hline BMI (higher) & & & $1.04 \dagger$ & .03 \\
\hline History of cancer & 1.89 & .04 & & \\
\hline History of cardiac surgery & 1.69 & .001 & & \\
\hline Dialysis & 3.14 & .004 & & \\
\hline BUN & & & $1.08 \ddagger$ & .009 \\
\hline INTERMACS level 1 & 4.58 & $<.0001$ & & \\
\hline INTERMACS level 2 & 2.35 & .02 & & \\
\hline Use of pulsatile LVAD & & & 2.63 & $<.0001$ \\
\hline RVAD in same operation & & & 3.22 & .002 \\
\hline \multicolumn{5}{|c|}{$\begin{array}{l}\text { INTERMACS, Interagency Registry for Mechanical Circulatory Support; } H R \text {, hazard } \\
\text { ratio; } B M I \text {, body mass index; } B U N, \text { blood urea nitrogen; } L V A D \text {, left ventricular assist } \\
\text { device; } R V A D \text {, right ventricular assist device. *The hazard ratio denotes the increased } \\
\text { risk from } 60 \text { to } 70 \text { years. } \dagger \text { The hazard ratio denotes the increased risk of a } 5 \text {-unit in- } \\
\text { crease in body mass index. } \ddagger \text { The hazard ratio denotes the increased risk of a } 10 \text {-unit } \\
\text { increase in blood urea nitrogen. }\end{array}$} \\
\hline
\end{tabular}




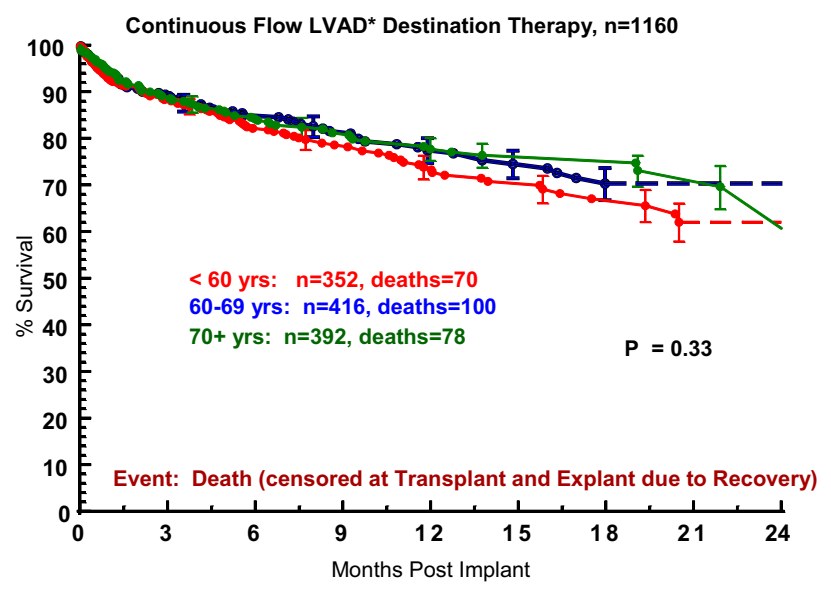

FIGURE 8. Actuarial survival after destination therapy left ventricular assist device ( $L V A D)$ support, stratified by age at implant. Patients are censored at transplant or explant for recovery. ${ }^{*}$ See notation in Figure 4.

Society for Heart and Lung Transplant Registry. ${ }^{5}$ The average 2-year risk-unadjusted survival in the most recent cohort is approximately $80 \%$ (Figure 16 ).

\section{Survival Justification for Potential Triage From Transplant to DT Therapy}

If we use the non-risk-adjusted 2-year transplant survival of $80 \%$ as an initial survival metric, generating solutions to the multivariate equation provides insight into patient subsets who would likely achieve the level of 2-year survival that might begin to compete with transplantation. Figure 17 depicts the age effect for a stable (INTERMACS level 3 or greater) patient with preserved renal function and without severe right ventricular failure who receives a continuous flow pump, stratified by the presence or absence of prior cardiac operations. For the patient with prior cardiac surgery, the $70 \%$ confidence limits overlap with a survival of at least $80 \%$ at 2 years for patients less than about 40 years of age; but for the patient without prior cardiac surgery, survival is likely to be at least $80 \%$ at 2 years for

TABLE 8. Patient profile level-Adult primary implants: INTERMACS, June 2006-December 2011, destination therapy

\begin{tabular}{|c|c|c|}
\hline Level & $\begin{array}{c}\text { June 2006-Dec } 2009 \\
(\mathbf{N}=156) \\
\text { No. }(\%) \\
\end{array}$ & $\begin{array}{c}\text { Jan 2010-Dec } 2011 \\
(\mathrm{~N}=1131) \\
\text { No. }(\%) \\
\end{array}$ \\
\hline 1. Critical cardiogenic shock & $29(18.6)$ & $110(9.7)$ \\
\hline 2. Progressive decline & $64(41.0)$ & $422(37.3)$ \\
\hline $\begin{array}{l}\text { 3. Stable but } \\
\text { inotrope-dependent }\end{array}$ & $36(23.1)$ & $346(30.6)$ \\
\hline 4. Recurrent advanced HF & $20(12.8)$ & 177 (15.6) \\
\hline 5. Exertion intolerant & $2(1.3)$ & $43(3.8)$ \\
\hline 6. Exertion limited & $3(1.9)$ & $21(1.9)$ \\
\hline 7. Advanced NYHA class III & $2(1.3) 8$ & $12(1.1)$ \\
\hline
\end{tabular}

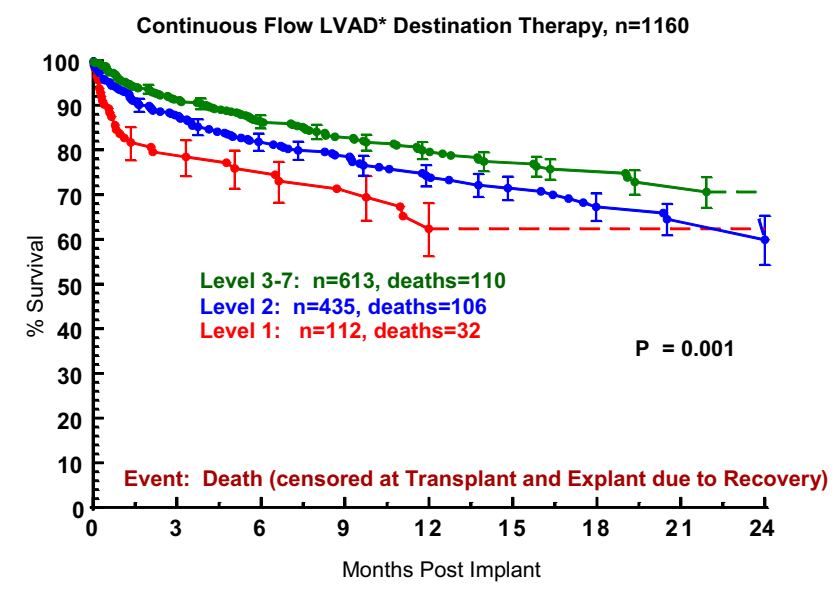

FIGURE 9. Actuarial survival after destination therapy left ventricular assist device ( $L V A D$ ) support, stratified by INTERMACS level at the time of implant. The INTERMACS levels are defined in Appendix Table 3. *See notation in Figure 4. INTERMACS, Interagency Registry for Mechanically Assisted Circulatory Support.

patients aged 62 years or less. Figure 18 displays the solution to the multivariable equation for a 60 -year-old patient with preserved renal function and without right ventricular failure who receives a continuous flow pump, depicted for various body mass indexes stratified by the presence or absence of prior cardiac surgery. Overall, about $20 \%$ of the DT population experienced 2-year survival equal to or greater than the transplant reference line of $80 \%$ (Figure 19).

\section{DISCUSSION}

\section{Evolution of DT}

As early as 1991, the Institute of Medicine recognized the importance of detailed longitudinal follow-up data on

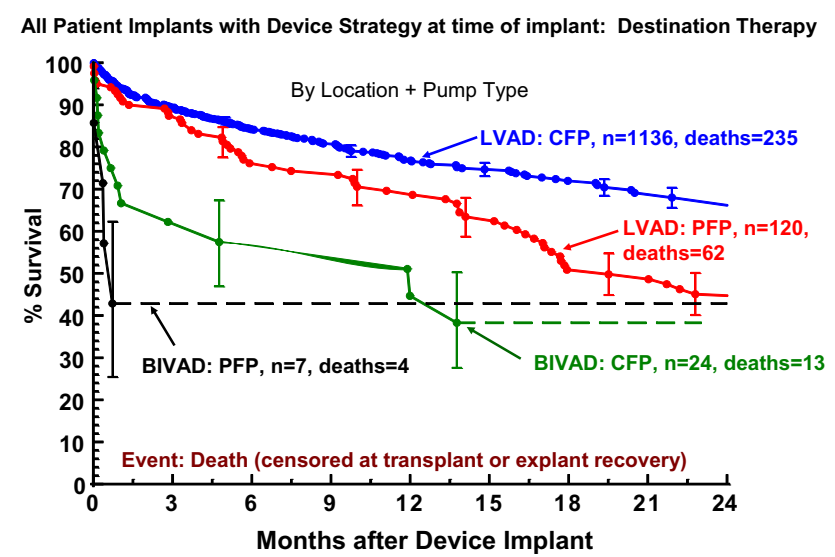

FIGURE 10. Actuarial survival after destination therapy left ventricular assist device ( $L V A D)$ support, stratified by device location and pump type. Patients are censored at transplant or device explant for recovery. $C F P$, Continuous flow pump; $P F P$, pulsatile flow pump; BIVAD, biventricular assist device (implanted at time of LVAD implant). 


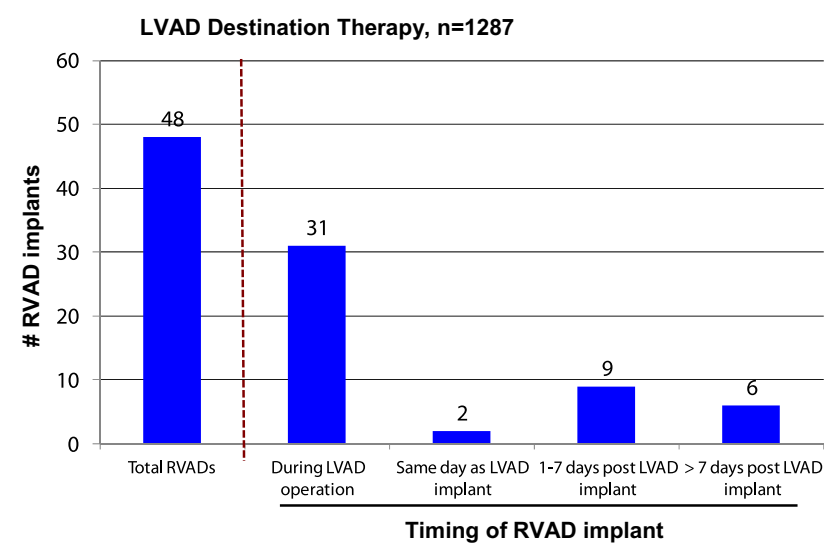

FIGURE 11. Bar chart indicating the timing of RVAD implant. $L V A D$, Left ventricular assist device; $R V A D$, right ventricular assist device.

patients receiving long-term MCS devices. Their report, "The Artificial Heart: Prototypes, Policies, and Patients," supported development of a registry to follow MCS patients for the remainder of their lives; "...maintaining a Registry of recipients should be considered a routine aspect of this care. The committee recommends that NHLBI support long-term studies." 6

After more than a decade of MCS as bridge-to-transplant therapy, the REMATCH (Randomized Evaluation of Mechanical Assistance for the Treatment of Congestive Heart Failure) trial (conducted between 1998 and 2001), ${ }^{7}$ paved the way for FDA approval of the HeartMate XVE for DT in the United States, followed by the CMS decision for Medicare coverage of DT in 2003. The prospect of widespread application of MCS as long-term therapy for patients with advanced heart failure provided the stimulus for the NHLBI to develop a platform for long-term follow-up of patients supported by MCS therapies. The resultant NHLBI

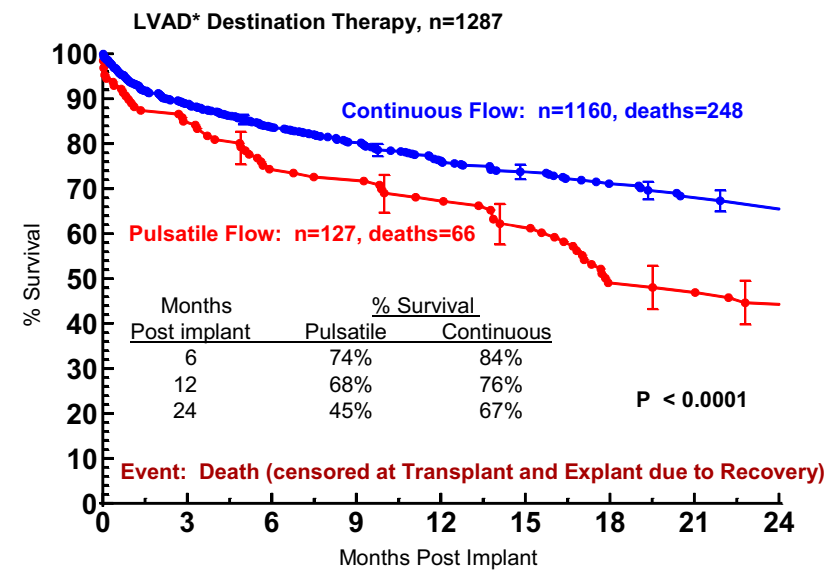

FIGURE 12. Actuarial survival among destination therapy patients, stratified by device type. Patients are censored at the time of transplant or explant due to recovery. $L V A D$, Left ventricular assist device. *See notation in Figure 4.
TABLE 9. Preimplant baseline characteristics: INTERMACS: Primary implants-Implant dates: June 23, 2006-December 31, 2011, destination therapy

\begin{tabular}{|c|c|c|c|}
\hline Preimplant characteristics & $\begin{array}{c}\text { PFP } \\
(\mathbf{N}=127)\end{array}$ & $\begin{array}{c}\text { CFP } \\
(\mathbf{N}=1160)\end{array}$ & $\begin{array}{c}P \\
\text { value }\end{array}$ \\
\hline Age (y) & 54.70 & 63.56 & $<.0001$ \\
\hline Albumin (g/dL) & 3.19 & 3.38 & .02 \\
\hline Total bilirubin (mg/dL) & 1.59 & 1.37 & .09 \\
\hline $\operatorname{BMI}\left(\mathrm{kg} / \mathrm{m}^{2}\right)$ & 32.40 & 28.14 & $<.0001$ \\
\hline $\mathrm{BNP}(\mathrm{pg} / \mathrm{mL})$ & 1286.82 & 1255.79 & .84 \\
\hline $\operatorname{BSA}\left(\mathrm{m}^{2}\right)$ & 2.27 & 2.04 & $<.0001$ \\
\hline BUN (mg/dL) & 38.83 & 33.91 & .01 \\
\hline Cholesterol (mg/dL) & 117.93 & 126.80 & .15 \\
\hline Cardiac index $\left(\mathrm{L} \cdot \mathrm{min}^{-1} \cdot \mathrm{m}^{-2}\right)$ & 2.09 & 2.15 & .64 \\
\hline Creatinine $(\mathrm{mg} / \mathrm{dL})$ & 1.81 & 1.54 & .02 \\
\hline $\mathrm{CRP}(\mathrm{mg} / \mathrm{L})$ & 23.47 & 14.43 & .39 \\
\hline Diastolic blood pressure $(\mathrm{mm} \mathrm{Hg})$ & 61.46 & 62.89 & .18 \\
\hline Hemoglobin $(\mathrm{mg} / \mathrm{dL})$ & 11.20 & 11.33 & .48 \\
\hline Heart rate & 9185 & 84.91 & $<.0001$ \\
\hline INR (international units) & 1.38 & 1.33 & .27 \\
\hline LVEDD & 6.81 & 6.74 & .58 \\
\hline Platelet $(\mathrm{K} / \mu \mathrm{L})$ & 199.29 & 187.06 & .09 \\
\hline Before albumin (mg/dL) & 15.30 & 18.85 & .0024 \\
\hline Protein C $(\%)$ & 77.17 & 84.70 & .59 \\
\hline Protein S (\%) & 70.29 & 77.47 & .54 \\
\hline Pulmonary diastolic pressure $(\mathrm{mm} \mathrm{Hg})$ & 29.35 & 24.61 & $<.0001$ \\
\hline Pulmonary systolic pressure (mm Hg) & 54.49 & 50.10 & .01 \\
\hline Pulmonary wedge pressure (mm Hg) & 26.75 & 23.21 & .0035 \\
\hline PVR (Wood units) & 3.08 & 2.75 & .31 \\
\hline RA pressure $(\mathrm{mm} \mathrm{Hg})$ & 15.75 & 11.35 & $<.0001$ \\
\hline SGOT/AST $(\mu / \mathrm{L})$ & 122.94 & 54.23 & .06 \\
\hline SGPT/ALT $(\mu / \mathrm{L})$ & 133.19 & 52.42 & .01 \\
\hline Sodium $(\mathrm{mmol} / \mathrm{L})$ & 134.23 & 134.99 & .13 \\
\hline Systolic blood pressure $(\mathrm{mm} \mathrm{Hg})$ & 99.40 & 104.90 & .0004 \\
\hline $\mathrm{WBC}(\mathrm{K} / \mu \mathrm{L})$ & 9.86 & 8.39 & .0008 \\
\hline
\end{tabular}

INTERMACS, Interagency Registry for Mechanical Assisted Circulatory Support; $P F P$, pulsatile flow pump; $C F P$, continuous flow pump; $B M I$, body mass index; $B N P$, brain natriuretic peptide; $B S A$, body surface area; $B U N$, blood urea nitrogen; $C R P$, C-reactive protein; $I N R$, international normalized ratio; $L V E D D$, left ventricular end-diastolic dimension; $P V R$, pulmonary vascular resistance; $R A$, right atrial; $S G O T /$ $A S T$, serum glutamic oxaloacetic transaminase/aspartate aminotransferase; $S G P T /$ $A L T$, serum glutamic pyruvate transaminase/alanine aminotransferase; $W B C$, white blood cell count.

contract laid the foundation for INTERMACS, as an extension of the earlier recommendations from the Institute of Medicine.

During the first 2 years of the INTERMACS experience, the landscape of approved device therapy was dominated by pulsatile technology, inasmuch as continuous flow pumps were largely still under investigation in clinical trials. ${ }^{8}$ With the general recognition that the HeartMate XVE device was prone to device malfunction with the frequent need for reoperation within 12 to 18 months (see again Figure 6), few such pumps were being implanted for DT. With escalating enthusiasm for continuous flow technology in Europe and the United States, many patients poorly suited for cardiac transplantation 


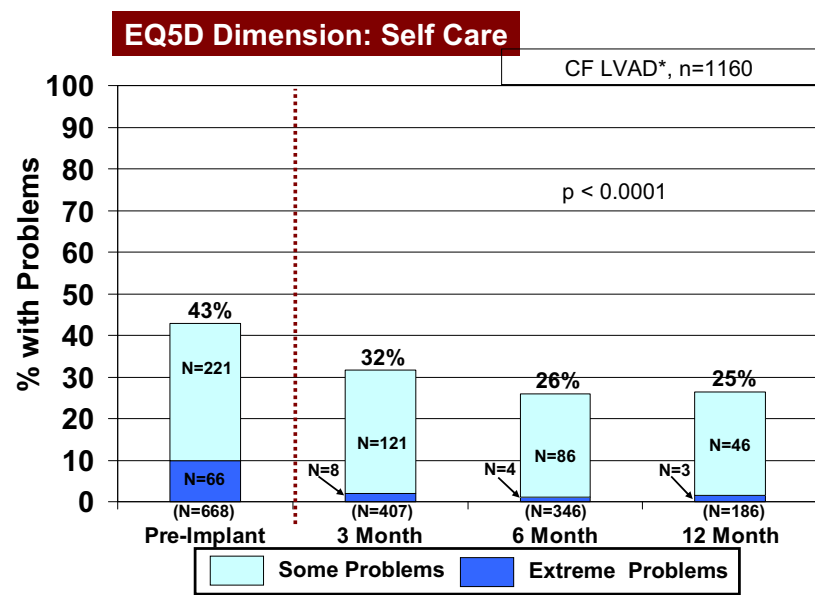

FIGURE 13. Percent of patients with some and extreme problems with self care before and at intervals after destination therapy with a continuous flow $(C F)$ left ventricular assist device ( $L V A D)$. EQ-5D, Standardized instrument designed as a measure of health outcome and applicable to a wide range of health conditions and treatments. See Materials and Methods for further discussion of EQ-5D.

received a continuous flow pump (approved for bridge-totransplant therapy in 2008) under the reimbursable approved indication of bridge to transplant. ${ }^{9}$ In reality, the transplant status of this group of patients was ambiguous, and MCS therapy was often applied as a strategy of "bridge to candidacy." 9 Predictably, VADs implanted as DT represented less than $10 \%$ of devices entered into INTERMACS between 2006 and 2009. ${ }^{10}$ The marked increase in pumps implanted as DT in 2010 and 2011 (more than $30 \%$ of total implants $)^{8}$ coincided with the approval of the HeartMate II continuous flow pump for DT in January of 2010.

This rapid evolution toward continuous flow technology is poignantly reflected in the INTERMACS registry

\section{EQ5D Dimension: Usual Activities}

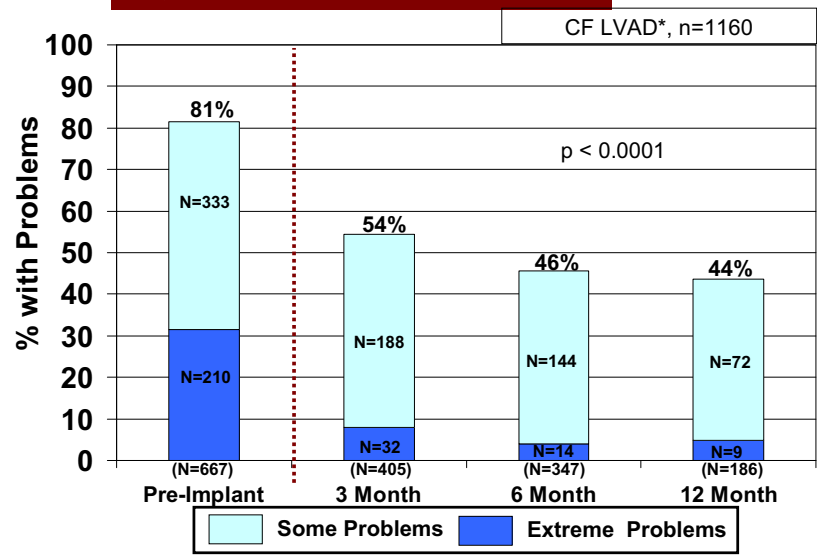

FIGURE 14. Percent of patients with some or extreme problems with usual activities before and at intervals after destination therapy with a continuous flow pump. The depiction and abbreviations are as in Figure 13. $C F$, Continuous flow; $L V A D$, left ventricular assist device.

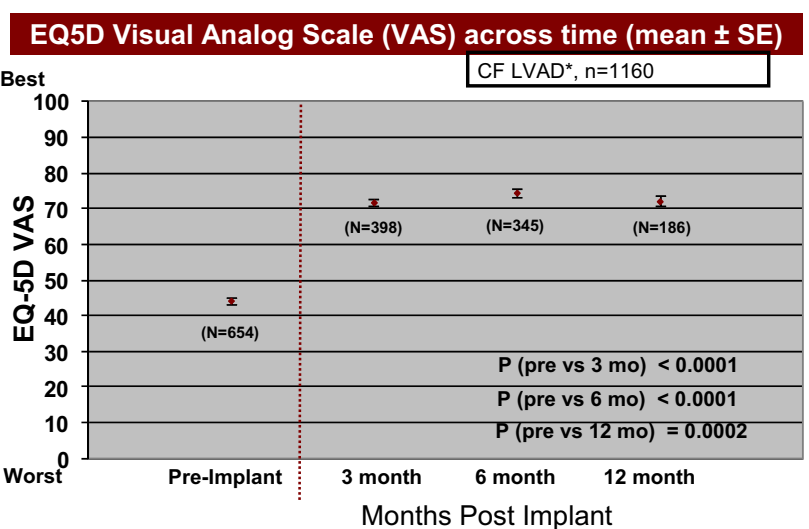

FIGURE 15. EQ-5D visual analog scale (VAS) (see Materials and Methods for definition) before and at intervals after destination therapy with a continuous flow pump. $S E$, Standard error; $C F$, continuous flow; $L V A D$, left ventricular assist device. The other abbreviations are as in Figure 13.

during the most recent era (see again Figure 2). Greater than $95 \%$ of devices entered into INTERMACS in 2010 and 2011 were continuous flow pumps, and all DT devices were continuous flow devices. ${ }^{9}$ The general enthusiasm for continuous flow devices in DT strategies was also supported by the multi-institutional study of Park and colleagues. $^{11}$

\section{Reasons for Transplant Ineligibility}

Despite the intended strategy of DT as a "permanent" therapy for advanced heart failure, the clinical reality is that few therapies are exclusively "either/or" for the

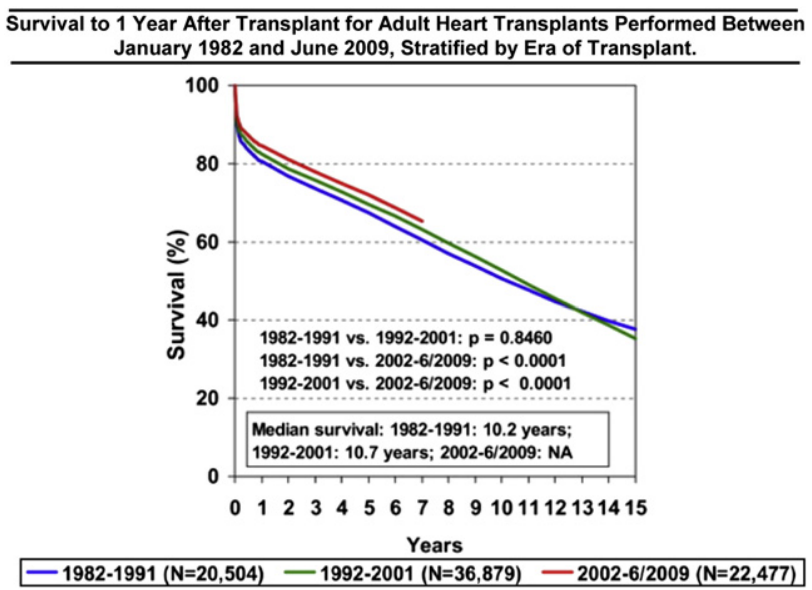

FIGURE 16. Survival after cardiac transplantation, stratified by era. $N A$, Not applicable. (From Stehlik J, Edwards LB, Kucheryavaya AY, Benden C, Christie JD, Dobbels F, et al. The Registry of the International Society for Heart and Lung Transplantation: Twenty-eighth Adult Heart Transplant Report-2011. J Heart Lung Transplant. 2011;30:1078-94. Reproduced with permission of the International Society for Heart and Lung Transplantation Registry.) 


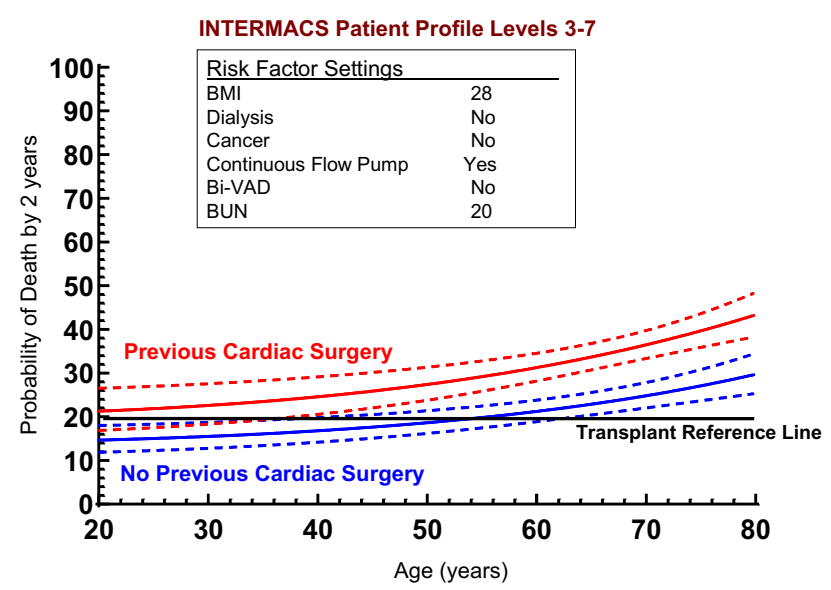

FIGURE 17. Solutions to the multivariable equation (see Appendix Table 5). The nomograms are generated with variables set as indicated for 2 patients according to age at implant. The dashed lines indicate the $70 \%$ confidence limits around the solution curve. BMI, Body mass index; Bi-VAD, biventricular support; $B U N$, blood urea nitrogen; INTERMACS, Interagency Registry for Mechanically Assisted Circulatory Support.

duration of the heart failure patient's life. Even with the most successful MCS, patients will be followed up indefinitely with scheduled reevaluations to determine whether the device, heart transplantation, explant, or potentially other therapies provide the greatest opportunity going forward for the highest quality extended survival. The appreciation of possible neutralization of certain transplant contraindications after device implant was previously addressed by Kirklin and colleagues ${ }^{10}$ in categorizing such contraindications as "modifiable" or "un-modifiable." The challenge of clinical prescience regarding the reversibility of many comorbid conditions is embodied in the designation "bridge to candidacy," which is currently the most

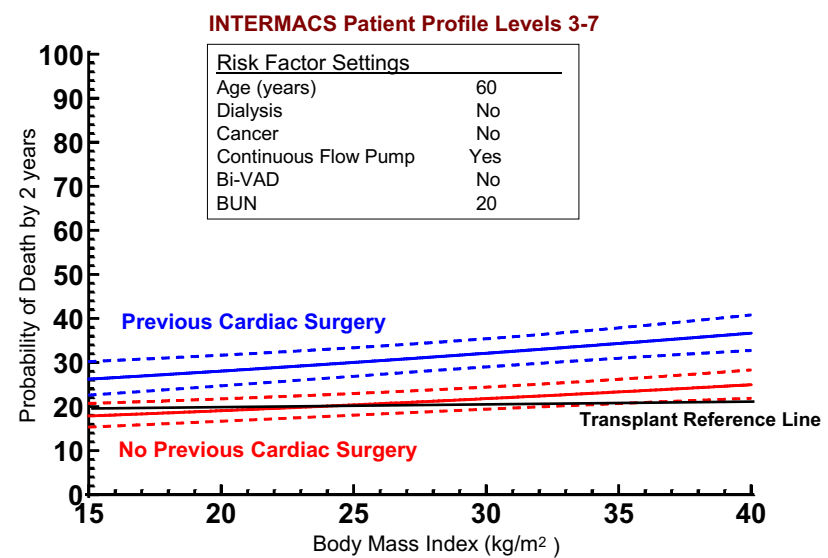

FIGURE 18. Solutions to the multivariable equation (see Appendix Table 5). The nomograms are generated with variables set as indicated for $2 \mathrm{pa}-$ tients according to body mass index. Depiction is as in Figure 17. BUN, Blood urea nitrogen; INTERMACS, Interagency Registry for Mechanically Assisted Circulatory Support; $B i-V A D$, biventricular support.

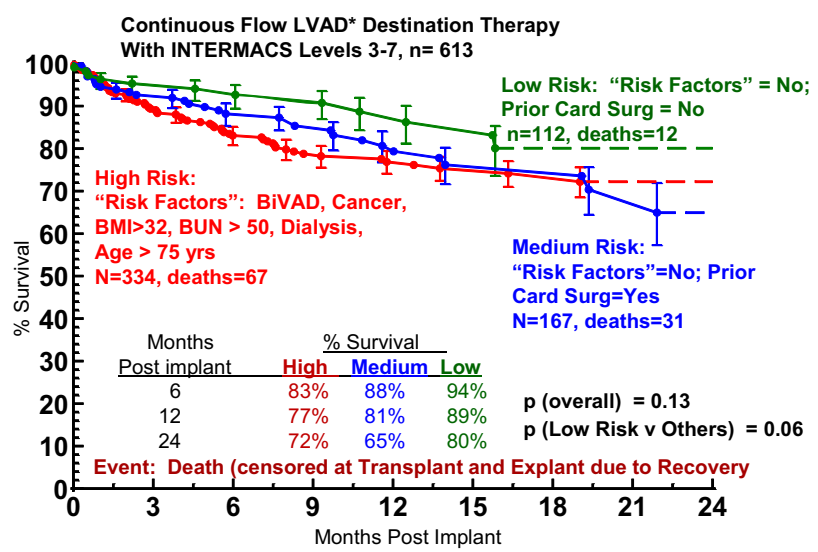

FIGURE 19. Actuarial survival stratified by high-, medium-, and low-risk patients. "Risk factors" include presence of biventricular support (BiVAD), previous cancer, body mass index $(B M I)$ greater than 32 , serum sodium less than 130, or blood urea nitrogen $(B U N)$ greater than 50. INTERMACS, Interagency Registry for Mechanically Assisted Circulatory Support; LVAD, left ventricular assist device.

common device strategy (not an FDA-approved indication) among implant recipients ${ }^{9}$ in INTERMACS.

\section{Outcome of Patients With Initial DT Strategy}

Despite the potential impurity of the designation DT as well as likely overlap (in terms of actually pursuing a course of long-term VAD therapy) with other strategy designations such as "bridge to candidacy," this study was well suited to critically analyze patients who received extended support with durable devices. Other studies have made inferences about "long-term" device therapy from patient populations ${ }^{8,12,13}$ ultimately committed to transplantation. The "censoring" of patients at time of transplant introduces considerable uncertainty about long-term device potential, in that patients with major device complications (which would likely affect patient survival and quality of life if the device was retained) often undergo transplantation at an increased priority level, thereby potentially avoiding an unfavorable VAD outcome. This study had relatively few such patients, in that only about $10 \%$ of pulsatile device patients underwent transplantation during the study period, and less than $5 \%$ of continuous flow patients (see again Figures 4 and 5) were diverted to transplant.

\section{Adverse Events}

In the evaluation of patients potentially suitable for either cardiac transplantation or MCS DT, the expected life satisfaction during extended support will ultimately exert a major influence on therapy selection for both practitioner and patient. In this sense, therapy comparison and selection is confounded by the striking differences in the adverse event profiles of heart transplantation versus MCS. Whereas transplantation is challenged by the complications of rejection, infection, malignancy, and allograft vasculopathy, ${ }^{14}$ 
the adverse event profile of the MCS patient is dominated by device-related infection, bleeding events, right heart failure, central nervous system events, and device malfunction. ${ }^{9,10,15}$ The concept of adverse event burden ${ }^{8}$ (see again Table 4) might provide a unifying method of expressing the overall adverse event impact of each therapy, but ultimately the patient will need to participate in therapy selection based, in part, on a subjective analysis of the relevant adverse event profile and how that might affect life satisfaction.

\section{Survival}

The pace of progress in effective extended MCS has been well chronicled since the original REMATCH publication cited a 2-year survival less than $25 \%$ with the HeartMate XVE as DT. ${ }^{7}$ Subsequent reports with the same pump technology reported 2-year survival of nearly $60 \% .^{11}$ With continuous flow technology as bridge-to-transplant therapy, 1-year survival improved from $68 \%$ in the original HeartMate II bridge-to-transplant trial ${ }^{12}$ to $73 \%$ in the midtrial update. ${ }^{11}$ In the subsequent HeartMate II DT trial, 2-year survival improved from $58 \%$ in the early trial experience to $63 \%$ for the midtrial group. ${ }^{11}$ The clear survival benefit of continuous flow technology over pulsatile pumps for DT was documented in the INTERMACS analysis of 2011. ${ }^{10}$ Other studies indicate that survival improvements have continued despite little change in overall patient risk profile over the past 4 years. ${ }^{9}$ The trajectory of incremental survival documented in this analysis is consistent with improvements in the field of MCS over the past 5 to 8 years.

\section{Risk Factors for DT}

The NYHA class IV designation has become the major descriptor of heart failure level sufficiently severe to warrant device therapy or transplantation, but it is widely recognized that this encompasses different levels of clinical decompensation. The current analysis identified patients in cardiogenic shock to be at higher risk for mortality with DT, a finding noted early in the INTERMACS experience. $^{8}$ This finding was facilitated by the INTERMACS subclassification of NYHA class IV for heart failure, in which 5 INTERMACS profiles describe the various stages of NYHA class IV (see again Appendix Table 3). After the first year of data collection, over $40 \%$ of patients receiving durable devices were in acute decompensation (level 1, cardiogenic shock). With the appreciation of the important increment of mortality associated with implantation under such unstable conditions, the proportion of patients receiving implants in shock fell to under $15 \%$ in $2010 .{ }^{9}$ Currently, increasing proportions of patients are currently implanted in the lower INTERMACS levels of NYHA class IV.

Right ventricular dysfunction severe enough to require RVAD support was the greatest predictor of subsequent mortality, which has been a consistent finding in prior INTERMACS analyses. ${ }^{2,8,9,10}$ Precise definitions of various degrees of right ventricular dysfunction have proved challenging and have been recently modified to better reflect clinical correlates (see Appendix Table 2). Even the identification of severe right ventricular failure by the need for RVAD support is rather subjective, inasmuch as the specific trigger for initiating RVAD placement differs among experienced VAD surgeons. The importance of identifying patients at risk for severe right ventricular failure is evident, inasmuch as such patients on the transplant list would be poor candidates for triage to DT VAD therapy. INTERMACS has viewed right ventricular dysfunction to be such a critical issue that a scientific task force is being assembled to address the issues of identification, prevention, and management of the failing right ventricle during LVAD support.

\section{Quality of Life}

The findings of improved quality-of-life indicators as judged by the EQ-5D instrument are consistent with improvements in quality of life and functional status using the Minnesota Living with Heart Failure Questionnaire. ${ }^{16,17}$ and the Kansas City Cardiomyopathy Questionnaire ${ }^{18}$ in the HeartMate II device trial. ${ }^{19,20}$ Other studies have shown substantial improvement in the 6-minute walk test after implant. ${ }^{20}$ Similar positive findings were reported by Park and colleagues. ${ }^{11}$ Although a myriad of studies have documented improvement in quality of life and functional outcome indicators after heart transplantation, ${ }^{21,22}$ few studies have directly compared transplantation with MCS. ${ }^{23}$

\section{Survival Justification to Triage From Transplant to DT Therapy}

The solutions to the risk factor model provide insight into the types of patients who, depending on their comorbidities for cardiac transplantation, might warrant consideration for triage to DT MCS with continuous flow technology. The profile of such patients would currently include preserved renal function, absence of severe right ventricular failure, stable cardiovascular function on inotropic support, and body mass index suitable for transplant. Currently, the model does not justify triage to DT if the patient has undergone previous cardiac operations except for relatively young patients, a group less likely to select long-term pump support unless they were highly sensitized. Although this model would not yet support tapping into the large cohort of patients with prior cardiac operations, details of that decision-making process would depend on risk factor modeling within the transplant population to seek subsets whose predicted 2-year survival might be less than $80 \%$. Realizing that inferences are being drawn from a group of patients considered ineligible for cardiac transplantation, the stratified actuarial depiction in Figure 19 suggests that nearly 
$20 \%$ of the actual DT patient population achieved survival that would be competitive with the "average" transplant patient.

If such triage decisions did occur, a paradigm shift of this magnitude in the arena of advanced heart failure would certainly accelerate the pace of device implants and potentially affect listing criteria at major heart transplant centers as well as allocation algorithms. Major challenges to ensure truly informed patient decisions regarding device therapy versus transplantation would further confound decisions in this evolving platform of heart failure care.

Of course, the primary metric would be survival, but survival at what interval? Is predicted 2-year survival of sufficient duration for such a paradigm shift? In great measure the answer depends on the "expected" trajectory of the survival curve beyond 2 years, inasmuch as the possibility appears remote that patients and providers will await 5 more years of patient follow-up, a randomized trial of VAD versus transplant, or other longitudinal analyses before beginning the "shift." Societal and health care "impatience" is already evident with the "REVIVE IT" trial, which allocates long-term device therapy possibly before the patient would normally be considered for transplantation.

Another imponderable in this therapeutic allocation process is the clear knowledge that the patients with a DT device can always be reconsidered for cardiac transplantation if device complications or other impairments in quality of life tip the balance toward transplantation. Other unintended consequences may occur: the whole priority allocation for other patients awaiting transplantation may be affected, and hospitals without expertise in transplant surgery and medicine may preferentially (and possibly inappropriately) offer devices rather than transplant to transplant-eligible patients.

Once this "magic metric" of survival (eg, $80 \%$ at 2 years) is accepted for devices in the advanced heart failure community, other metrics that majorly affect the quality of patient existence will assume center stage in our ongoing analyses. For just that reason, quality of life and functional outcome indicators represent a major INTERMACS focus in future analyses.

In considering specific patients for triage from transplantation to device therapy, the presence of noncardiac comorbidities is known to impair long-term survival after cardiac transplantation, as has been quantified in an analysis from the Cardiac Research Database. ${ }^{24}$ Another important group of patients for potential triage are those who are highly sensitized with circulating anti-HLA antibodies. The opportunity for DT could provide an important benefit for these sensitized patients who frequently endure long waiting times while continuing to experience symptoms of advanced heart failure. Ultimately, the triage of these higher risk transplant subsets could increase the survival utility of the precious and limited resource of donor hearts.

\section{Study Limitations}

Inferences from this database have important strengths and weaknesses. The strengths include the scope and rigor of INTERMACS. As an NHLBI initiative, INTERMACS engages National Institutes of Health oversight, follows Observational Study Monitoring Board surveillance, and requires performance standards of participating institutions. The power of INTERMACS is further enhanced by the CMS mandate for data submission on all approved and consented durable MCS devices implanted at centers approved for DT therapy, formal definitions and processes for adjudication of adverse events, dedicated electronic data submission, compulsive data monitoring, and a hospital auditing process, all of which raise INTERMACS close to the rigor of a clinical trial. Indeed, the quality and completeness of data collection have been of sufficient quality that the FDA has embraced the use of INTERMACS patients as "concurrent controls" in at least 1 pivotal clinical device trial, ${ }^{25}$ and the INTERMACS platform has been held in high regard by the NHLBI. ${ }^{1}$

However, important study limitations relate to the knowledge that INTERMACS does not represent a complete sample of DT patients. Follow-up is not available for patients who do not provide informed consent, which represents about $9.6 \%$ of available patients with FDA-approved devices. One could speculate about whether these patients represent a higher risk group. Furthermore, all patients who receive DT therapy as part of a clinical device trial are excluded from INTERMACS. Finally, maximal follow-up of continuous flow DT patients is only now exceeding 2 years, generating uncertainty about truly longterm survival.

\section{CONCLUSIONS}

1. DT represents an increasing LVAD application and currently accounts for nearly one third of overall MCS activity in the United States.

2. Evolution from pulsatile to continuous flow technology has dramatically improved 1- and 2-year survivals.

3. DT is not appropriate for patients with rapid hemodynamic deterioration or cardiogenic shock.

4. The presence of severe right ventricular failure is a contraindication for DT.

5. Important subsets of DT patients now enjoy survival that may be competitive with heart transplantation out to about 2 years.

6. Future studies will focus on transplant-eligible subsets who may benefit from informed discussions about MCS as an alternative long-term option.

We acknowledge the skilled participation of Ms Susan Meyers in all areas of the analyses and Ms Peggy Holmes in manuscript preparation. 


\section{References}

1. Miller MA, Ulisney K, Baldwin JT. INTERMACS (Interagency Registry for Mechanically Assisted Circulatory Support): a new paradigm for translating registry data into clinical practice. J Am Coll Cardiol. 2010;56:738-40.

2. Kirklin JK, Naftel DC, Stevenson LW, Kormos RL, Pagani FD, Miller MA, et al. INTERMACS database for durable devices for circulatory support: first annual report. J Heart Lung Transplant. 2008;27:1065-72.

3. Stevenson LW, Pagani FD, Young JB, Jessup M, Miller L, Kormos RL, et al. INTERMACS profiles of advanced heart failure: first definition. J Heart Lung Transplant. 2009;28:535-41

4. McGiffin DC, Naftel DC, Kirklin JK, Morrow WR, Towbin J, Shaddy R, et al. Predicting outcome after listing for heart transplantation in children: comparison of Kaplan-Meier and parametric competing risk analysis. Pediatric Heart Transplant Study Group. J Heart Lung Transplant. 1997;16:713-22.

5. Stehlik J, Edwards LB, Kucheryavaya AY, Benden C, Christie JD, Dobbels F, et al. The Registry of the International Society for Heart and Lung Transplantation: Twenty-eighth Adult Heart Transplant Report-2011. J Heart Lung Transplant. 2011;30:1078-94.

6. Institutes of Medicine. The artificial heart: prototypes, policies and patients. Washington (DC): The National Academies Press; 1991

7. Rose EA, Gelijns AC, Moskowitz AJ, Heitjan DF, Stevenson LW, Dembitsky W, et al. Randomized Evaluation of Mechanical Assistance for the Treatment of Congestive Heart Failure (REMATCH) Study Group. Long-term use of a left ventricular assist device for end-stage heart failure. N Engl J Med. 2001;345: 1435-43.

8. Kirklin JK, Naftel DC, Kormos RL, Stevenson LW, Pagani FD, Miller MA, et al. Second INTERMACS annual report: more than 1,000 primary left ventricular assist device implants. J Heart Lung Transplant. 2010;29:1-10.

9. Kirklin JK, Naftel DC, Kormos RL, Stevenson LW, Pagani FD, Miller MA, et al. The Fourth INTERMACS Annual Report: 4,000 implants and counting. J Heart Lung Transplant. 2012;31:117-26.

10. Kirklin JK, Naftel DC, Kormos RL, Stevenson LW, Pagani FD, Miller MA, et al. Third INTERMACS Annual Report: the evolution of destination therapy in the United States. J Heart Lung Transplant. 2011;30:115-23.

11. Park SJ, Milano CA, Tatooles AJ, Rogers JG, Adamson RM, Steidley DE, et al. Outcomes in advanced heart failure patients with left ventricular assist devices for destination therapy. Circ Heart Fail. 2012;5:241-8.

12. Miller LW, Pagani FD, Russell SD, John R, Boyle AJ, Aaronson KD, et al. HeartMate II Clinical Investigators. Use of a continuous-flow device in patients awaiting heart transplantation. $N$ Engl J Med. 2007;357:885-96.

13. Starling RC, Naka Y, Boyle AJ, Gonzalez-Stawinski G, John R, Jorde U, et al. Results of the post-U.S. Food and Drug Administration-approval study with a continuous flow left ventricular assist device as a bridge to heart transplantation: a prospective study using the INTERMACS (Interagency Registry for Mechanically Assisted Circulatory Support). J Am Coll Cardiol. 2011;57:1890-8.

14. Kirklin JK, Young JB, McGiffin DC. Heart transplantation. Philadelphia: Churchill Livingston; 2002.

15. Aissaoui N, Borgermann J, Gummert J, Morshuis M. HeartWare continuous-flow ventricular assist device thrombosis: The Bad Oeynhausen experience. J Thorac Cardiovasc Surg. 2012;143:e37-9.

16. Pagani FD, Miller LW, Russell SD, Aaronson KD, John R, Boyle AJ, et al, HeartMate II Investigators. Extended mechanical circulatory support with a continuous-flow rotary left ventricular assist device. J Am Coll Cardiol. 2009;54: 312-21.

17. Rector TS, Kubo SH, Cohn JN. Validity of the Minnesota Living with Heart Failure questionnaire as a measure of therapeutic response to enalapril or placebo. Am J Cardiol. 1993;71:1106-7.

18. Spertus J, Peterson E, Conard MW, Heidenreich PA, Krumholz HM, Jones P, et al. Monitoring clinical changes in patients with heart failure: a comparison of methods. Am Heart J. 2005;150:707-15.

19. Starling RC. Improved quanity and quality of life: a winning combination to treat advanced heart failure. J Am Coll Cardiol. 2010;55:1835-6.

20. Rogers JG, Aaronson KD, Boyle AJ, Russell SD, Milano CA, Pagani FD, et al. Continuous flow left ventricular assist device improves functional capacity and quality of life of advanced heart failure patients. J Am Coll Cardiol. 2010;55: 1826-34.

21. Grady KL, Jalowiec A, White-Williams C. Predictors of quality of life in patients at one year after heart transplantation. J Heart Lung Transplant. 1999;18:202-10.

22. Grady KL, Naftel DC, White-Williams C, Bellg AJ, Young JB, Pelegrin D, et al. Predictors of quality of life at 5 to 6 years after heart transplantation. $J$ Heart Lung Transplant. 2005;24:1431-9.
23. Kugler C, Malehsa D, Tegtbur U, Guetzlaff E, Meyer AL, Bara C, et al. Health related quality of life and exercise tolerance in recipients of heart transplants and left ventricular assist devices: a prospective, comparative study. J Heart Lung Transplant. 2011;30:204-10.

24. Kirklin JK, Naftel DC. Mechanical circulatory support: registering a therapy in evolution. Circ Heart Fail. 2008;1:200-5.

25. Aaronson KD, Slaughter MS, McGee E, Cotts WG, Acker MA, Jessup ML. Evaluation of the HeartWare HVAD left ventricular assist device system for the treatment of advanced heart failure: results of the ADVANCE bridge to transplant trial. Circ Res. 2010;122:2216.

\section{Discussion}

Dr Soon J. Park (Rochester, Minn). Dr Kirklin and his colleagues are to be congratulated for this timely and important presentation. They report that a significant fraction of DT patients are achieving a survival that is comparable with that of those who undergo heart transplantation. Such finding is especially astonishing in that these patients, by definition, were those deemed inappropriate to allocate donor hearts for the concern of poor posttransplant outcome.

Perhaps it is helpful to revisit the medical ethics governing heart transplantation, which was established well before the current development in LVAD therapy. Heart transplantation has been the only therapeutic option capable of prolonging life in these patients with end-stage heart failure. Although it is highly effective on an individual level, its epidemiologic impact has been trivial for there exists a significant mismatch between donors and recipients. The donor heart remains a precious and scarce resource for society. Therefore, the practice of heart transplantation has been guided by principles of justice, utility, and transplant benefit to maximize the number of years gained by the transplantation.

With the recent development in LVAD therapy, heart transplant no longer seems to be the only viable option. Now, LVAD therapy can be rendered immediately and abundantly, and it is going to change the natural history of patients with end-stage heart failure dramatically, whether transplant eligible or not.

As we have just been informed by Dr Kirklin, a significant fraction of patients who were destined to die because heart transplant was not an option, a typical scenario of despair that affects the vast majority of patients, are now able to enjoy life on LVAD support.

In regard to the transplant-eligible patients, many medical centers seem to witness a significantly enhanced rate of survival in these bridge-to-transplant patients compared with DT patients What is the INTERMACS bridge-to-transplant experience? How does it compare with the attrition rate of $4 \%$ due to various causes such as rejection, infection, allograft vasculopathy, and malignancy after transplantation? What would be the appropriate LVAD strategy in terms of patient selection, duration of support, and timing of triggering transplantation in accordance with the principles of transplantation? Finally, would it ever make sense to consider LVAD as the primary therapy and reserve heart transplantation as a secondary therapy?

I would welcome Dr Kirklin's insight into some of these questions, and, once again, congratulations for ushering in a truly exciting period of LVAD therapy.

Dr Kirklin. Thank you, Dr Park. Those are interesting questions. 
You asked about the mortality or attrition rate with cardiac transplantation versus ventricular support. In the INTERMACS database, recall that the continuous flow technology is really now only exceeding 2 years, and during that time in the low-risk group, the mortality rate is about $10 \%$ per year, which compares with about $6 \%$ per year in the constant phase after cardiac transplantation. Thus it is not quite there yet, even though there are specific risk factor groups that are competitive out to 2 years. Of course, the mechanical support group includes older patients; the median age in the INTERMACS DT group was 67 years versus 55 years in the transplant group.

Regarding the issue of using LVAD therapy as primary therapy and transplantation secondary, of course, the goal in the future will be to have an array of therapies that maximizes long-term survival for patients. Whether that means initial VAD therapy followed by transplant or initial transplant followed by a total artificial heart will depend on the kinds of rigorous analyses that we will need to do in the future. There is going to be the requirement for rigorous transplant databases to get risk-appropriate patients as well as ongoing analyses of these mechanical support databases.

Dr John V. Conte (Baltimore, Md). Dr Kirklin, congratulations on a very thought-provoking paper. Having heard you say about 2 years ago that mechanical support would not be equivalent of heart transplantation at this point in time, it is refreshing to hear that you have somewhat changed your tone based on these data. Are you ready right now to refer this subset of patients for mechanical support rather than transplantation? If not, what duration of long-term follow-up would you consider necessary before you would refer that subset of patients you just presented?

Finally, is there a financial consideration in referring this subgroup of patients for long-term therapy? What role do the economics of transplantation and mechanical support play in this decision?

Dr Kirklin. The actual identification of patients on the transplant list who could be triaged to mechanical support will depend, of course, on their comorbidities, and there are analyses available from previous experiences that would allow us to begin that triage effort. Currently, however, it is going to be challenging, because there is more contemporary data about risk stratification in MCS patients, ironically, than there is in the current era of cardiac transplantation. It is appropriate to begin triaging certain patients-those with multiple comorbidities who are likely to have a long wait for cardiac transplantation, such as sensitized patients.
The financial implications are complicated and will have to be determined by societal as well as medical priorities. Clearly, we are going to be looking at the financial implications over decades of patient care if we are going to be using a combination of mechanical support, transplantation, and potentially other therapies.

Dr Conte. To answer the question directly, are you ready as you stand there today to refer that subgroup of patients for DT as opposed to transplantation? I am going to hang you on your words.

Dr Kirklin. Yes.

Dr R. Duane Davis (Durham, $N C$ ). Congratulations. I just want to be a little bit cautious when you use that $20 \%$ 2-year survival in heart transplant as your benchmark and then compare a 40-yearold who has never had surgery getting a VAD and saying it is equivalent. If you did a 40 -year-old who never had previous cardiac surgery, the 2-year mortality would not be $20 \%$ after a heart transplant. It is clear that continuous VAD is getting into the ballpark, but I am not sure I am ready to agree that it is equivalent.

Finally, when are we going to be ready to randomize between those 2 therapies?

Dr Kirklin. The challenge in transplantation is to begin to set some benchmark about which we could begin to have this discussion, and I think a benchmark of $20 \%$ mortality at 2 years is certainly reasonable. Remember that the low-risk, 40-year-old patient undergoing cardiac transplantation without important other comorbidities is not the patient one would want to triage to mechanical support. The reason this benchmark is important is to begin the discussion of those kinds of patients who could potentially be triaged if they are a low enough risk with device therapy. However, it will only be those patients who are on the transplant list with multiple adverse comorbidities that we are going to initially select for triage. It will not be the otherwise healthy 40 -year-old man with a good long-term expectation from cardiac transplantation.

Dr Joseph Amato (Chicago, Ill). Dr Kirklin, Dr Pagani, I congratulate you on your work. Last week, I was at the FDA meeting in regard to the INTERMACS pump. I witnessed the pump in action, and all the other committee members there approved this dynamic pump. I disagree with the comments made in regard to the continued improvement in searching for a bridge to transplant and that the impact as mentioned is trivial. The experience in Europe has been highly successful and we await a smaller version. It is a compact and beautiful little pump. 
APPENDIX TABLE 1. Information collected in the interagency registry for mechanically assisted circulatory support database

\begin{tabular}{|c|c|c|c|c|c|}
\hline Data collected & Preimplant & Implant & $1 \mathrm{wk} / 1 \mathrm{mo}$ & Discharge & 3 mo/every 6 mo \\
\hline Demographic & $\mathrm{x}$ & & & & \\
\hline Medical support status & $\mathrm{x}$ & & & & \\
\hline Comorbidities & $\mathrm{x}$ & & & & \\
\hline Hemodynamics & $\mathrm{X}$ & & $\mathrm{x}$ & $\mathrm{x}$ & $\mathrm{x}$ \\
\hline Medications & $\mathrm{x}$ & & $\mathrm{x}$ & $\mathrm{x}$ & $\mathrm{x}$ \\
\hline Laboratory & $\mathrm{x}$ & & $\mathrm{x}$ & $\mathrm{x}$ & $\mathrm{x}$ \\
\hline Medical condition & $\mathrm{x}$ & & $\mathrm{x}$ & & $\mathrm{x}$ \\
\hline Exercise function & $\mathrm{x}$ & & & & $\mathrm{x}$ \\
\hline Patient status & $\mathrm{x}$ & & & & $\mathrm{x}$ \\
\hline Device information & & $\mathrm{x}$ & & & \\
\hline Device details & & $\mathrm{X}$ & & & \\
\hline Device parameters & & & & $\mathrm{x}$ & $\mathrm{X}$ \\
\hline Quality of life & $\mathrm{X}$ & & & & $\mathrm{X}$ \\
\hline Trail Making Test & $\mathrm{x}$ & & & & $\mathrm{x}$ \\
\hline Adverse event reminders & & & $\mathrm{x}$ & $\mathrm{X}$ & $\mathrm{x}$ \\
\hline Chronology of hospital time & & & & $\mathrm{x}$ & \\
\hline
\end{tabular}




APPENDIX TABLE 2. Major adverse events collected in
INTERMACS

Major Bleeding

AN EPISODE OF SUSPECTED INTERNAL OR EXTERNAL BLEEDING THAT RESULTS IN ONE OR MORE OF THE FOLLOWING:

1. Death

2. Reoperation

3. Hospitalization

4. Transfusion of red blood cells

If TRANSFUSION IS SELECTED, then apply the following rules: During first $7 \mathrm{~d}$ after implant:

- Adults $(\geq 50 \mathrm{~kg})$ : $\geq 4 \mathrm{U}$ of packed red blood cells within any 24 hour period during the first $7 \mathrm{~d}$ after implant.

After $7 \mathrm{~d}$ following implant

- Any transfusion of packed red blood cells after $7 \mathrm{~d}$ following implant with the investigator recording the number of units given.

Note: Hemorrhagic stroke is considered a neurologic event and not as a separate bleeding event.

\section{Cardiac Arrhythmias}

Any documented arrhythmia that results in clinical compromise (eg, diminished VAD flow, oliguria, presyncope, or syncope) that requires hospitalization or occurs during a hospital stay. Cardiac arrhythmias are classified as 1 of 2 types:

1. Sustained ventricular arrhythmia requiring defibrillation or cardioversion.

2. Sustained supraventricular arrhythmia requiring drug treatment or cardioversion.

\section{Pericardial Fluid Collection}

Accumulation of fluid or clot in the pericardial space that requires surgical intervention or percutaneous catheter drainage. This event will be subdivided into those with clinical signs of tamponade (eg, increased central venous pressure and decreased cardiac/VAD output) and those without signs of tamponade.

\section{Device Malfunction}

Device malfunction denotes a failure of one or more of the components of the MCS device system that either directly causes or could potentially induce a state of inadequate circulatory support (low cardiac output state) or death. The manufacturer must confirm device failure. A failure that was iatrogenic or recipient-induced will be classified as an Iatrogenic/Recipient-induced Failure.

Device failure should be classified according to which components fails as follows:

1. Pump failure (blood-contacting components of the pump and any motor or other pump-actuating mechanism that is housed with the blood-contacting components). In the special situation of pump thrombosis, thrombus is documented to be present within the device or its conduits that result in or could potentially induce circulatory failure.

2. Nonpump failure (eg, external pneumatic drive unit, electric power supply unit, batteries, controller, interconnect cable, compliance chamber).

\section{Hemolysis}

A plasma-free hemoglobin value that is greater than $40 \mathrm{mg} / \mathrm{dL}$, in association with clinical signs associated with hemolysis (eg, anemia, low hematocrit, hyperbilirubinemia) occurring after the first $72 \mathrm{~h}$ after

\section{APPENDIX TABLE 2. Continued}

implant. Hemolysis related to documented non-device-related causes (eg, transfusion or drug) is excluded from this definition.

\section{Hepatic Dysfunction}

An increase in any 2 of the following hepatic laboratory values (total bilirubin, aspartate aminotransferase/AST and alanine aminotranferease/ALT) to a level greater than 3 times the upper limit of normal for the hospital, beyond $14 \mathrm{~d}$ after implant (or if hepatic dysfunction is the primary cause of death).

\section{Hypertension}

New-onset blood pressure elevation greater than or equal to $140 \mathrm{~mm} \mathrm{Hg}$ systolic or $90 \mathrm{~mm} \mathrm{Hg}$ diastolic (pulsatile pump) or $110 \mathrm{~mm} \mathrm{Hg}$ mean pressure (rotary pump).

Pediatric patients: For patients under $18 \mathrm{y}$ of age weighing less than $50 \mathrm{~kg}$, hypertension is defined as systolic, diastolic, or mean blood pressure greater than the 95th percentile for age that requires the addition of intravenous or oral therapy for management.

\section{Major Infection}

A clinical infection accompanied by pain, fever, drainage, and/or leukocytosis that is treated by antimicrobial agents (nonprophylactic). A positive culture from the infected site or organ should be present unless strong clinical evidence indicates the need for treatment despite negative cultures. The general cateogories of infection are listed below:

\section{Localized Nondevice Infection}

Infection localized to any organ system or region (eg, mediastinitis) without evidence of systemic involvement (see sepsis definition), ascertained by standard clinical methods and either associated with evidence of bacterial, viral, fungal or protozoal infection, and/or requiring empirical treatment.

\section{Percutaneous Site and/or Pocket Infection}

A positive culture from the skin and/or tissue surrounding the driveline or from the tissue surrounding the external housing of a pump implanted within the body, coupled with the need to treat with antimicrobial therapy, when there is clinical evidence of infection such as pain, fever, drainage, or leukocytosis.

\section{Internal Pump Component, Inflow or Outflow Tract Infection}

Infection of blood-contacting surfaces of the LVAD documented by positive site culture. (There should be a separate data field for paracorporeal pump that describes infection at the percutaneous cannula site, eg, Thoratec PVAD).

\section{Sepsis}

Evidence of systemic involvement by infection, manifested by positive blood cultures and/or hypotension.

\section{Myocardial Infarction}

Two categories of myocardial infarction will be identified:

\section{Perioperative Myocardial Infarction}

The clinical suspicion of myocardial infarction together with creatine kinase MB or troponin greater than 10 times the local hospital upper limits of normal, found within $7 \mathrm{~d}$ after VAD implant together with electrocardiographic findings consistent with acute myocardial infarction. (This definition uses the higher suggested limit for serum markers owing to apical coring at the time of VAD placement and does not use wall motion changes because the apical sewing ring inherently creates new wall motion abnormalities.)

(Continued) 


\section{APPENDIX TABLE 2. Continued}

\section{Nonperioperative Myocardial Infarction}

The presence more than $7 \mathrm{~d}$ after implant of 2 of the following 3 criteria:

1. Chest pain that is characteristic of myocardial ischemia

2. Electrocardiogram with a pattern or changes consistent with a myocardial infarction

3. Troponin or creatine kinase (measured by standard clinical pathology/laboratory medicine methods) greater than the normal range for the local hospital with positive MB fraction ( $\geq 3 \%$ total creatine kinase). This should be accompanied by a new regional left or right ventricular wall motion abnormality on a myocardial imaging study.

\section{Neurologic Dysfunction}

Any new, temporary or permanent, focal or global neurologic deficit ascertained by a standard neurologic examination (administered by a neurologist or other qualified physician and documented with appropriate diagnostic tests and consultation note). The examining physician will distinguish between a transient ischemic attack, which is fully reversible within $24 \mathrm{~h}$ (and without evidence of infarction), and a stroke, which lasts longer than $24 \mathrm{~h}$ (or $<24 \mathrm{~h}$ if there is evidence of infarction). The NIH Stroke Scale (for patients $>5$ y old) must be readministered at 30 and $60 \mathrm{~d}$ after the event to document the presence and severity of neurologic deficits. Each neurologic event must be subcategorized as:

1. Transient ischemic attack (acute event that resolves completely within $24 \mathrm{~h}$ with no evidence of infarction)

2. Ischemic or hemorrhagic cardiovascular accident (event that persists beyond $24 \mathrm{~h}$ or $<24 \mathrm{~h}$ associated with infarction on an imaging study.

In addition to the above, for patients less than 6 mo of age, any of the following:

3. New abnormality of head ultrasound

4. Electroencephalogram positive for seizure activity with or without clinical seizure

\section{Psychiatric Episode}

Disturbance in thinking, emotion or behavior that causes substantial impairment in functioning or marked subjective distress requiring intervention. Intervention is the addition of new psychiatric medication, hospitalization, or referral to a mental health professional for treatment. Suicide is included in this definition.

\section{Renal Dysfunction}

Two categories of renal dysfunction will be identified:

\section{Acute Renal Dysfunction}

Abnormal kidney function requiring dialysis (including hemofiltration) in patients who did not require this procedure before implant, or a rise in serum creatinine of greater than 3 times baseline or greater than 5 $\mathrm{mg} / \mathrm{dL}$ (in children, creatinine greater than 3 times the upper limit of normal for age) sustained for over $48 \mathrm{~h}$.

\section{Chronic Renal Dysfunction}

An increase in serum creatinine of $2 \mathrm{mg} / \mathrm{dL}$ or greater above baseline, or requirement for hemodialysis sustained for at least $90 \mathrm{~d}$.

\section{Respiratory Failure}

Impairment of respiratory function requiring reintubation, tracheostomy, or (for patients >age $5 \mathrm{y}$ ) the inability to discontinue ventilatory support within $6 \mathrm{~d}(144 \mathrm{~h})$ after VAD implant. This excludes intubation for reoperation or temporary intubation for diagnostic or therapeutic procedures.

\section{APPENDIX TABLE 2. Continued}

\section{Right Heart Failure}

Symptoms and signs of persistent right ventricular dysfunction (central venous pressure $>18 \mathrm{~mm} \mathrm{Hg}$ with a cardiac index $<2.0 \mathrm{~L} \cdot \mathrm{min}^{-1} \cdot \mathrm{m}^{-2}$ in the absence of elevated left atrial/pulmonary capillary wedge pressure [greater than $18 \mathrm{~mm} \mathrm{Hg}$ ], tamponade, ventricular arrhythmias, or pneumothorax) requiring RVAD; implantation; or requiring inhaled nitric oxide or inotropic therapy for a duration of more than 1 week at any time after LVAD implantation."

\section{Arterial Non-Central Nervous System Thromboembolism}

An acute systemic arterial perfusion deficit in any noncerebrovascular organ system owing to thromboembolism confirmed by 1 or more of the following:

1. Standard clinical and laboratory testing

2. Operative findings

3. Autopsy findings

This definition excludes neurologic events.

\section{Venous Thromboembolism Event}

Evidence of venous thromboembolic event (eg, deep vein thrombosis, pulmonary embolism) by standard clinical and laboratory testing.

\section{Wound Dehiscence}

Disruption of the apposed surfaces of a surgical incision, excluding infectious etiology, and requiring surgical repair.

\section{Other}

An event that causes clinically relevant changes in the patient's health (eg, cancer)

INTERMACS, Interagency Registry for Mechanically Assisted Circulatory Support; $V A D$, Ventricular assist device; MCS, Mechanical circulatory support; $L V A D$, Lef ventricular assist device; $R V A D$, Right ventricular assist device; $P V A D$, paracorporeal ventricular assist device; $N I H$, National Institutes of Health. 
APPENDIX TABLE 3. INTERMACS (Preimplant) Levels: Levels 1 through 5 are degrees of NYHA class IV

INTERMACS 1: Critical cardiogenic shock describes a patient who is "crashing and burning," in which a patient has life-threatening hypotension and rapidly escalating inotropic pressor support, with critical organ hypoperfusion often confirmed by worsening acidosis and lactate levels.

INTERMACS 2: Progressive decline describes a patient who has been demonstrated "dependent" on inotropic support but nonetheless shows signs of continuing deterioration in nutrition, renal function, fluid retention, or other major status indicators. Patient profile 2 can also describe a patient with refractory volume overload, perhaps with evidence of impaired perfusion, in whom inotropic infusions cannot be maintained owing to tachyarrhythmias, clinical ischemia, or other intolerance.

INTERMACS 3: Stable but inotrope dependent describes a patient who is clinically stable on mild to moderate doses of intravenous inotropes (or has a temporary circulatory support device) after repeated documentation of failure to wean without symptomatic hypotension, worsening symptoms, or progressive organ dysfunction (usually renal). It is critical to monitor nutrition, renal function, fluid balance, and overall status carefully to distinguish between a patient who is truly stable at patient profile 3 and a patient who has unappreciated decline rendering them patient profile 2 . This patient may be either at home or in the hospital.

INTERMACS 4: Resting symptoms describes a patient who is at home on oral therapy but frequently has symptoms of congestion at rest or with activities of daily living. He or she may have orthopnea, shortness of breath during activities of daily living such as dressing or bathing, gastrointestinal symptoms (abdominal discomfort, nausea, poor appetite), disabling ascites, or severe lower extremity edema. This patient should be carefully considered for more intensive management and surveillance programs, by which some may be recognized to have poor compliance that would compromise outcomes with any therapy.

INTERMACS 5: Exertion intolerant describes a patient who is comfortable at rest but unable to engage in any activity, living predominantly within the house or housebound. This patient has no congestive symptoms but may have chronically elevated volume status, frequently with renal dysfunction, and may be characterized as exercise intolerant.

INTERMACS 6: Exertion limited also describes a patient who is comfortable at rest without evidence of fluid overload, but who is able to do some mild activity. Activities of daily living are comfortable and minor activities outside the home such as visiting friends or going to a restaurant can be performed, but fatigue results within a few minutes of any meaningful physical exertion. This patient has occasional episodes of worsening symptoms and is likely to have had a hospitalization for heart failure within the past year. This category describes NYHA class IIIB.

INTERMACS 7: Advanced NYHA class III describes a patient who is clinically stable with a reasonable level of comfortable activity, despite a history of previous decompensation that is not recent. This patient is usually able to walk more than a block. Any decompensation requiring intravenous diuretics or hospitalization within the previous month should make this person a patient profile 6 or lower.

INTERMACS, Interagency Registry for Mechanically Assisted Circulatory Support; NYHA, New York Heart Association.
APPENDIX TABLE 4. Variables examined in risk factor analysis

\begin{tabular}{|c|}
\hline Demographics \\
\hline Age \\
\hline Male \\
\hline White \\
\hline Black \\
\hline Height, $\mathrm{cm}$ \\
\hline Weight, $\mathrm{kg}$ \\
\hline Body surface area (BSA) \\
\hline Marital status \\
\hline Laboratory value \\
\hline Sodium \\
\hline Albumin \\
\hline Bilirubin \\
\hline Blood urea nitrogen (BUN) \\
\hline Creatinine \\
\hline Cholesterol \\
\hline Clinical \\
\hline Protein C \\
\hline C-reactive protein (CRP) \\
\hline Blood type \\
\hline Diagnosis-congenital \\
\hline Diagnosis—coronary artery disease \\
\hline History of coronary artery bypass grafting (CABG) \\
\hline History of cardiac surgery \\
\hline Implantable cardiac defibrillator (ICD) \\
\hline Inotropes \\
\hline Diabetes \\
\hline Chronic obstructive pulmonary disease (COPD) \\
\hline Ascites \\
\hline Peripheral vascular disease \\
\hline Cardiovascular accident \\
\hline Previous cancer \\
\hline Current smoker \\
\hline Alcohol abuse \\
\hline New York Heart Association (NYHA) \\
\hline Hemodynamics \\
\hline Systolic blood pressure \\
\hline Left ventricular ejection fraction $<20$ \\
\hline Patient profile levels \\
\hline Level 1 \\
\hline Level 2 \\
\hline Level 3 \\
\hline Level 4 \\
\hline Level 5 \\
\hline Level 6 \\
\hline Level 7 \\
\hline Implant information \\
\hline Left ventricular assist device (LVAD) \\
\hline Right ventricular assist device (RVAD) \\
\hline Biventricular assist device (BIVAD) \\
\hline Concomitant surgery \\
\hline Left ventricular assist device, continuous flow \\
\hline Left ventricular assist device, pulsatile flow \\
\hline Preimplant interventions \\
\hline Ventilator \\
\hline Dialysis \\
\hline Intra-aortic balloon pump \\
\hline
\end{tabular}


APPENDIX TABLE 5. Multivariable equations for risk models

The parametric model is specified in the cumulative hazard (A) domain as the sum of 2 phases:

$\Lambda(t, \Theta)=\sum_{j=1}^{\mathrm{J} *} \mu_{j}\left(x_{j}, \beta_{j}\right) G_{j}\left(t, \Theta_{j}\right)$

Where $t$ is time, $\mu_{\mathrm{j}}$ is the log-linear parametric scaling function of

concomitant information, and $G j$ is the parametric shaping function for each of the 2 phases.

The hazard function $\lambda$ is the time derivative of the cumulative hazard function

$\lambda(t, \Theta)=\sum_{j=1}^{\mathrm{J}} \mu_{j}\left(x_{j}, \beta_{j}\right) g_{j}\left(t, \Theta_{j}\right)$

Early hazard phase:

$$
\begin{aligned}
& G_{\mathrm{t}}=\left[1+\left(\frac{B(t)}{\rho}\right)^{1 / \mathrm{v}}\right]^{1 / \mathrm{m}} \\
& g_{\mathrm{t}}=\left[1+\left(\frac{B(t)}{\rho}\right)^{1 / \mathrm{v}}\right]^{-\frac{1}{\mathrm{~m}}-1}\left(\frac{B(t)}{\rho}\right)^{\frac{1}{\mathrm{v}}} \frac{\partial B(t)}{\partial t} \frac{1}{m \mathrm{v} \rho} \\
& \rho=B\left(t_{1 / 2}\right)\left[2^{\mathrm{m}}-1\right]^{\mathrm{v}}
\end{aligned}
$$

Constant hazard phase:

$$
\text { and } \begin{aligned}
& G_{2}=t \\
& g_{2}=1
\end{aligned}
$$

The maximum likelihood estimates of the parameters are:

$\mathrm{t}_{1 / 2}=1.0868$

$\nu=1.0316$

$\mathrm{m}=1.0$

$\mu_{\mathrm{e}}=0.04381$

$\mu_{\mathrm{c}}=0.00615$ 